\title{
Computational modelling and experimental tank testing of the multi float WaveSub under regular wave forcing
}

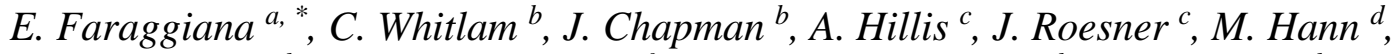 \\ D. Greaves ${ }^{d}, Y-H . \mathrm{Yu}^{e}$, K. Ruehl $^{f}$, I. Masters $^{a}$, G. Foster ${ }^{b}$, G. Stockman $^{b}$ \\ ${ }^{a}$ Marine Energy Research Group, Zienkiewicz Centre for Computational Engineering, College of \\ Engineering, Swansea University,951180@swansea.ac.uk, i.masters@swansea.ac.uk \\ ${ }^{b}$ Marine Power Systems Ltd., Swansea, UK, contact@marinepowersystems.co.uk \\ ${ }^{c}$ University of Bath, A.J.Hillis@bath.ac.uk,j.roesner@bath.ac.uk \\ ${ }^{d}$ University of Plymouth, Plymouth, UK, martyn.hann@plymouth.ac.uk, \\ deborah.greaves@plymouth.ac.uk \\ ${ }^{e}$ National Renewable Energy Laboratory, Golden, CO,USA, Yi-hsiang.Yu@nrel.gov \\ ${ }^{f}$ Sandia National Laboratories, Albuquerque, NM, USA kmruehl@sandia.gov
}

\section{Introduction}

\begin{abstract}
A submerged wave device generates energy from the relative motion of floating bodies. In WaveSub, three floats are joined to a reactor; each connected to a spring and generator. Electricity generated damps the orbital movements of the floats. The forces are non-linear and each float interacts with the others. Tuning to the wave climate is achieved by changing the line lengths so there is a need to understand the performance trade-offs for a large number of configurations. This requires an efficient, large displacement, multidirectional, multi-body numerical scheme. Results from a 1/25 scale wave basin experiment are described. Here we show that a time domain linear potential flow formulation (Nemoh, WEC-Sim) can match the tank testing provided that suitably tuned drag coefficients are employed. Inviscid linear potential models can match some wave device experiments, however, additional viscous terms generally provide better accuracy. Scale experiments are also prone to mechanical friction and we estimate friction terms to improve the correlation further. The resulting error in mean power between numerical and physical models is approximately $10 \%$. Predicted device movement shows a good match. Overall, drag terms in time domain wave energy modelling will improve simulation accuracy in wave renewable energy device design.
\end{abstract}

Keywords—Renewable energy; wave energy; tank testing; wave potential theory; damping

Renewable energy from waves has been studied for many years [1] and a comprehensive review of device designs is given by Falcao [2]. This paper considers the Marine Power Systems Ltd. (MPS) WaveSub device [3], which is a subsurface point absorber where the components move relative to one another. Power capture is enhanced by orbital motion of the floats to capture both heave and surge energy in a similar way to the Bristol Cylinder [4]. A further notable feature of the design is the use of the reactor as a self-installing barge so that the unit can easily be towed to site. Following extensive testing at the University of Plymouth Ocean basin [5], a single float device has undergone sea trials at FabTest [6]. Figure 1 shows the device under tow. 


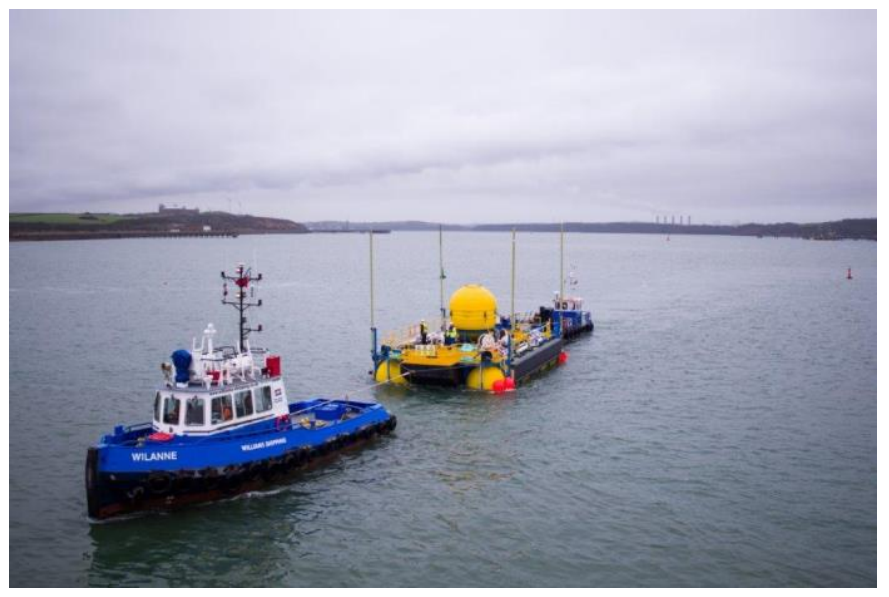

Figure 1: Single float WaveSub on tow, showing the reaction barge in surface configuration with float parked in centre. (Single column image)

One embodiment of a multi-float WaveSub is characterized by a set of three floats in a line perpendicular to the predominant wave direction. They are all connected by lines to a single reactor body. A modular design approach is used so that the multi float system is comprised of three single float-reactor systems connected together. The power take-off is also modular with a separate module for each float tether.

This paper is the result of work to understand if such a system could be accurately modelled using both linear potential flow theory and dynamic system modelling [7]. Experiments of the response of the device in a test tank for various regular wave cases provide confidence in the numerical model and to understand more clearly the limits of the model.

Nemoh [8] is based on linear potential flow theory and is used to find the hydrodynamic coefficients for the simulation of the dynamic system. This code is open-source and validated [9, 10] against a well-known commercial code WAMIT [11]. However, Nemoh presents some unsolved problems. Firstly, the software creates some irregular frequencies that lead to nonphysical predictions of the hydrodynamic coefficients. Secondly, errors can be introduced if there are thin elements in the mesh because the solver is based on a source distribution [8]. This second problem applies in this case due to the geometry of the reactor of the WaveSub device (the depth is an order of magnitude less than the other 2 size dimensions), so a check of the hydrodynamic coefficients is necessary to understand this limitation.

The basis of the dynamic system modelling is the WEC-Sim (Wave Energy Converter Simulator) open-source tool [12]. Development and maintenance of the WEC-Sim code is funded by the U.S. Department of Energy's Water Power Technologies Office by the National Renewable Energy 
Laboratory and Sandia National Laboratories. The code is developed in MATLAB/SIMULINK using the multi-body dynamics solver Simscape Multibody. WEC-Sim has the ability to model devices that are comprised of rigid bodies, power-take-off systems, and mooring systems. Articulated multibody WECs, hydrodynamic interactions, Morison elements and quasi-static mooring can also be accounted for. Simulations are performed in the time-domain by solving the governing WEC equations of motion in 6 degrees-of-freedom.

This code has been validated previously, for example for a heaving two-body point absorber (RM3) consisting of a float and a spar/plate [13]. Then a Wave Energy Converter Code Comparison (WEC3) was conducted to compare different mid-fidelity codes [14]. InWave, WaveDyn, ProteusDS and WEC-Sim have been considered to simulate a floating three-body Oscillating Flap device both in regular and irregular waves and accounting for hydrodynamic viscous drag. Good agreement was found between these codes and WEC-Sim has been further improved since then to account for hydrodynamic body-to-body interactions. The Ocean Energy Systems (OES) Task 10 Wave Energy Converter modelling verification [15] aimed to establish confidence in existing numerical models, understanding their limits and differences. Using the example of the motion and power output of a heaving sphere as a comparison between different codes showed that weak nonlinear codes such as WEC-Sim that consider nonlinear hydrostatics and Froude-Krylov forcing should be more accurate compared to linear codes but more computationally demanding. WEC-Sim simulation data has also been compared with experimental results of a rigid floating body constrained to heave and surge motion during the competition launched by the Center for Ocean Energy Research (COER) [16]. Good agreement was obtained in the surge motion but the agreement in heave was excellent; the difference in surge is thought to be due to high sensitivity to small discrepancies between numerical setup and experimental setup. Finally, WEC-Sim phase 1 validation testing considered device characterization of a Floating Oscillating Surge Wave Energy Converter (FOSWEC) [17-18]. These results were based on decay tests that were used to determine which numerical features are the most important to model the FOSWEC dynamics.

Testing of WaveSub was conducted in two different sessions in 2017 in the University of Plymouth Ocean basin [19]. The device was tested in 1/25th Froude scale and was related to the concept validation phase (TRL 1-3) investigating the variation of design variables [20]. The main aim was to compare the power produced by a single float device to a three float configuration. This project was part funded by Innovate UK under the Energy Catalyst Round 3 Early Stage competition. MPS designed and constructed the WEC float and reactor and pulley systems; the University of 
Bath designed and built the PTO, control and data logging systems; the University of Plymouth operated the test facility. Figure 2 shows the test model in the tank with a three float configuration. The aim of the test was to observe power capture for different float-to-float spacings and floatreactor separations. Different spring stiffness and damping values of the PTO were also applied, testing active and passive PTO modes. The specific configuration parameters used in the experimental test were used to set up the numerical simulation. For clarity, in this paper we show detailed comparison between the numerical model approach used and the tank testing for different regular waves but for a specific configuration of float spacing, float-reactor separation and PTO. This work aims to understand the limitations of the numerical approach used to estimate the motion and the power produced from a multi-float configuration of the WaveSub device.

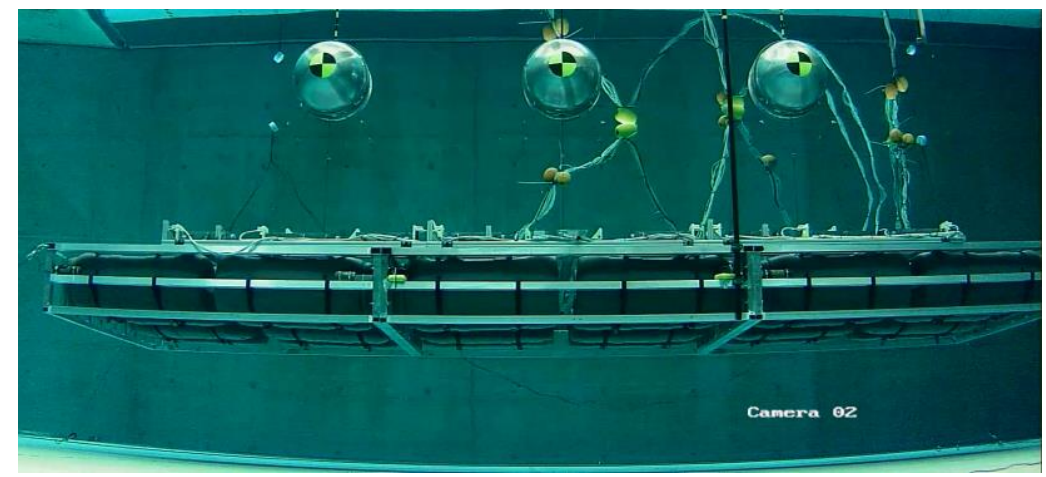

Figure 2: Multi-float model shown in its static position at a medium reactor depth and 2.25D float spacing. (Single column image)

\section{Material and methods}

\subsection{Experimental set-up}

Figure 3 shows the experimental test in the Ocean Basin, raised out of the water on a movable floor. This shows three floats in a "parked" condition above the reactor. Inertia ballast is given by the black 100L water tanks. Overall, the model was $6.19 \mathrm{~m}$ long at 1:25 scale. Motion data has been obtained using the Qualisys system [21] while the wave elevation was recorded by using 6 wave probes ( 3 in the front and 3 in the back of the device). Rotational speed and position of each of the PTO line drums was collected by non-contact Renishaw RM44 encoders. Load cells are used to measure the tension in each PTO and mooring line. 


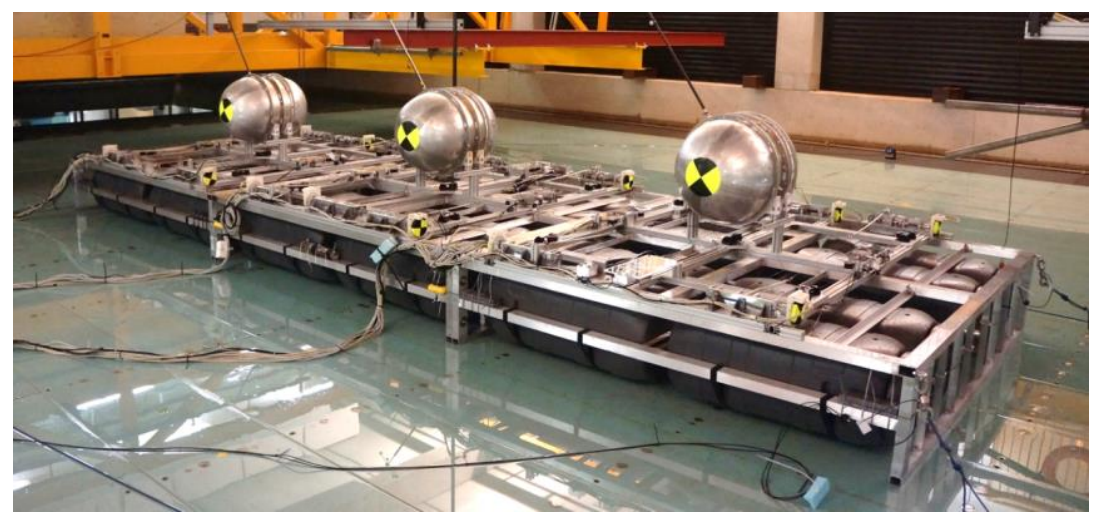

Figure 3: Multi float device shown here in 3D horizontal float spacing before tank floor lowered for testing. Taken during May/June 2017 testing period. (Single column image)

An overall view of the experimental campaign is shown in Figure 4. Qualisys marker poles were set-up on each float and one on the reactor. Encoders, load cells and motors were all onboard the reactor platform while the detailed position of the wave gauges are described in Figure 4 . The observed relative error between the requested basin control target incident wave height and the measured wave height was around 5.6\%. This difference is comprised of three components: the inherent accuracy of the tank control; reflections from the model and wave reflection effects from the sides and beach of the tank. The model is small compared to the tank and the nearest gauge is $2.5 \mathrm{~m}$ from the model, therefore reflections from the model will be negligible. Wave reflection effects were minimised through two precautionary approaches. Firstly, the runs were not started until the model was completely settled and steady. Secondly, visual inspection of wave gauges and video footage showed that reflection effects were interfering in a negligible way on the incident regular wave. As a further mitigation of any influence of waves, the wave climate used as input to the numerical model is the time history measured in the tank. This implicitly includes reflection effects as an input to the virtual model device and therefore there is less requirement to explicitly separate the reflected wave field as the reflections are also present in the numerical approximation of the tank test. 


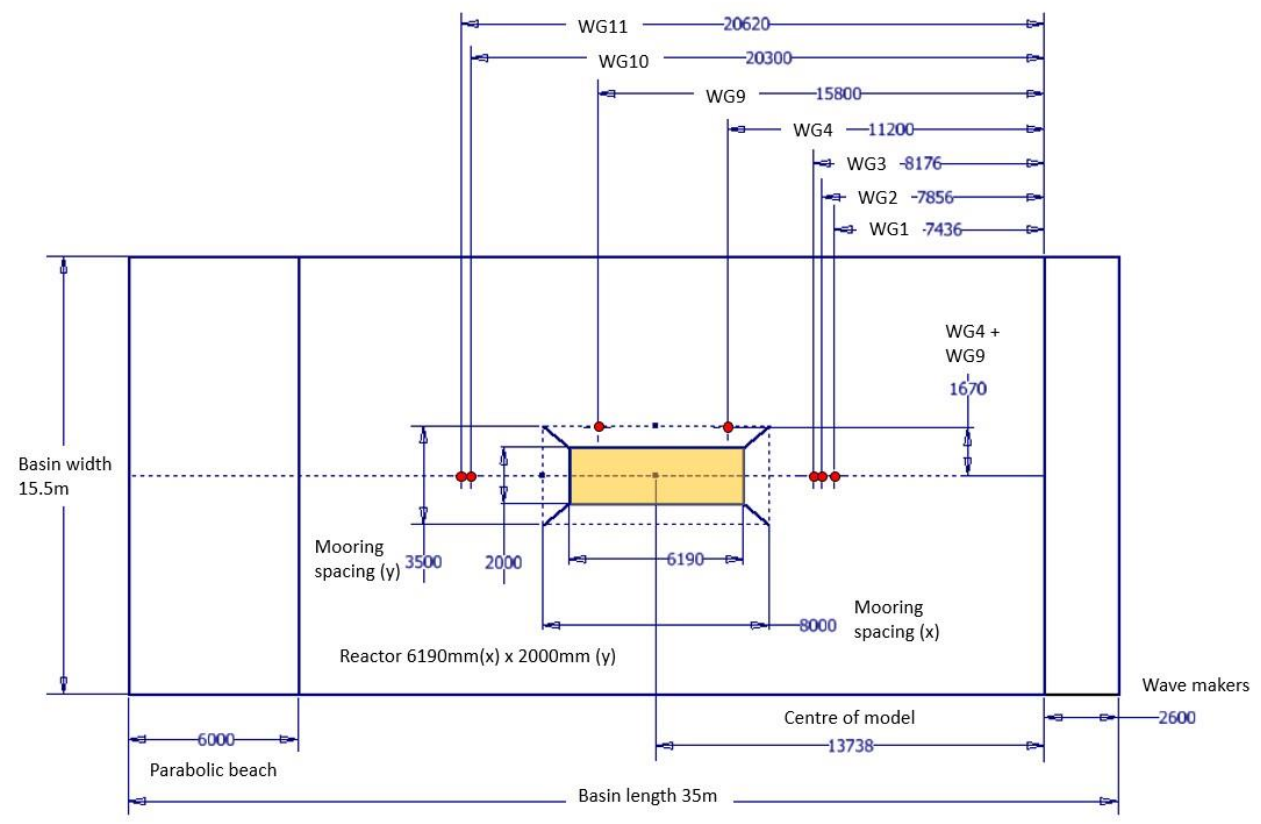

Figure 4: Drawing of the experimental campaign at tank scale. (2-column image)

The wave condition tested were the followings:

\begin{tabular}{|c|c|c|}
\hline Water depth (m) & Wave height (m) & Wave period (s) \\
\hline \multirow[t]{6}{*}{75} & \multirow[t]{6}{*}{4} & 7.5 \\
\hline & & 8.5 \\
\hline & & 9 \\
\hline & & 9.5 \\
\hline & & 10 \\
\hline & & 10.5 \\
\hline
\end{tabular}

Table 1: Regular wave properties at full scale.

The components are constructed as follows (measurements are referred to 1:25 scale):

The floats were characterized by a central cylinder and two hemispheres on the ends. They were manufactured from $2 \mathrm{~mm}$ thick aluminium. Flange rings welded externally to the central cylinder were designed with different holes to allow the testing of different PTO line attachment angles. Three different horizontal float spacings were tested based on multiples of the diameter of the float. The spacings chosen were 2.25, 3 and 4 times the diameter of the float between the outer surfaces. The results here report on the 2.25 diameter spacing tests.

The reactor contained a number of different parts: the reactor frame, the reactor ballast tanks, the reactor ballast and the PTO frame. The reactor frame was designed and manufactured from aluminium box section welded together to form an individual module, three of these modules were then bolted together to form a single structure. The ballast tanks were $100 \mathrm{~L}$ water butts and there 
were 8 for each reactor module. These ballast tanks were flooded with water during testing and used to increase the inertia properties of the reactor. Other lead ballast on the top of the reactor was attached to decrease the mooring line tensions to more suitable values. Finally, the PTO frames were designed to be adapted to different float spacing configurations and were bolted to the top surface of each reactor frame in different positions accordingly.

The PTO system was based around an electrical system to minimise friction and to provide precise control. The key components consisted of an electric generator/motor Maxon EC90 flat [22] 48V, with RM44 encoders from RLS [23]. The motors could be driven by float motion as generators when connected to a variable resistance load bank, in the form of Ohmite rheostats [24] (RJS50RE, $50 \Omega, 50 \mathrm{~W})$. This allowed passive testing with variable damping rates. The PTO motors could also be actively controlled in four quadrants to enable the testing of advanced control strategies. An initial benchmarking experiment of the PTO was used to characterise the torque-speed relationship as shown in figure 5. Due to the control system employed, a linear relationship between the PTO line drum rotational speed and motor torque was obtained with a very high $R^{2}$ value.

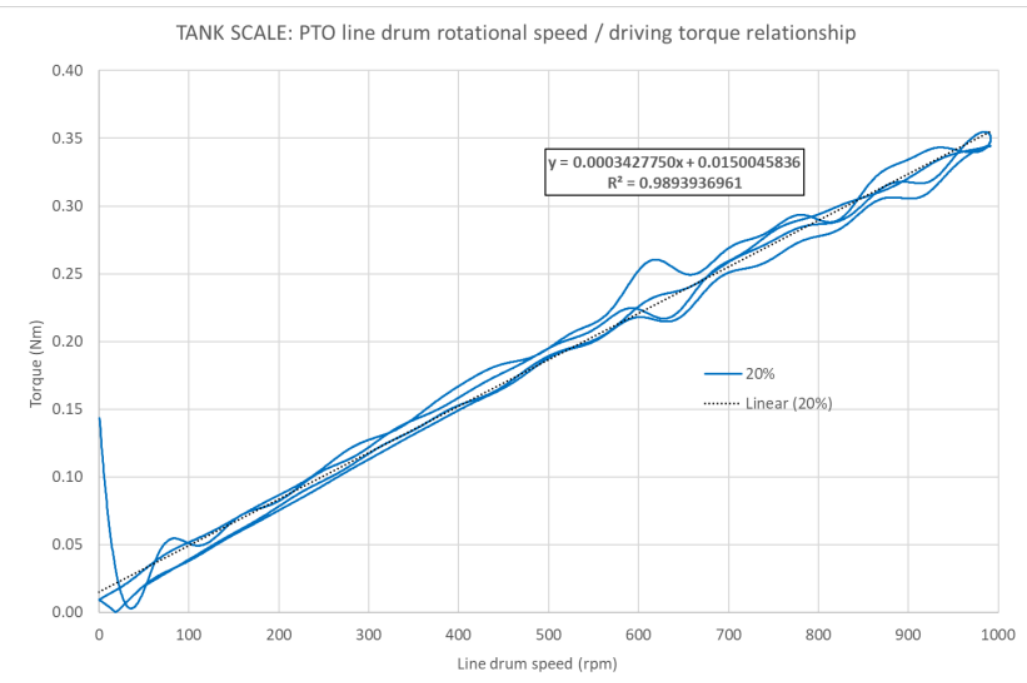

Figure 5: The tank scale PTO line speed / driving torque relationship. The percentage in the legend shows one particular setting of load / damping on the load bank. (Single column image)

Real time control and data logging of sensor and actuator signals was achieved using SIMULINK RealTime with a NI PCI-6225 Multifunction DAQ. The control loop executed at a sampling rate of $2 \mathrm{kHz}$ and logging at a rate of $100 \mathrm{~Hz}$.

Five float tethers connect each float to the reactor: 4 in the corners (spring/damping PTO) and one in the centre (spring only). The central tether was designed to compensate for buoyancy therefore reducing the tensions on the corner tethers. A target buoyancy distribution of $90 \%$ on the central 
line and $10 \%$ shared between the corners was designed. The stiffness value of each PTO was related to the specific spring attached to that line, the four corner lines were identical and the centre line was different. The spring of the central PTO line used rubber bands normally used for spearfishing, 1x Omer 20mm band and 2x SFS $18.5 \mathrm{~mm}$ band in combination. The corner springs were $1 \mathrm{x}$ Theraband silver tube [25], as used in therapeutic exercise.

The mooring connected the reactor to the seabed with 4 taut, diagonal mooring lines in the corners with a spread of $3500 \mathrm{~mm}$ in $\mathrm{x}$ and $8000 \mathrm{~mm}$ in $\mathrm{y}$.

\subsection{Computational model set-up}

When comparing physical and numerical models, it is important to decide the scale of each of the tests. To assist the design team for the WaveSub device, the numerical model was based upon the dimensions of the full scale design. Moreover, the hydrodynamic calculation in Nemoh shows a better computational stability when larger dimensions are used. In order to compare with the tank test, the experimental results have been scaled from the testing scale using Froude scaling. This scaling is valid for the majority of the forces in the system: hydrodynamic forces from Nemoh depend only on the geometry and wave frequencies and so they can be Froude scaled; PTO and mooring forces are linearized and so they can be also Froude scaled. However, to improve the match between numerical and experimental models, viscous drag forces have been used in WECSim. The drag forces obtained are realistic for tank testing scale but they will scale differently for full scale. A more realistic numerical model of the full scale device should account for the influence of the Reynolds number on the drag together with scaling effects of realistic PTO and mooring forces.

There are different steps to simulate numerically a wave device as it is described also in [26]. First a $\mathrm{CAD} /$ mesh software is used for the mesh generation of the different hydrodynamic bodies that describe the wave energy device. Salome-Meca [27] has been chosen because it is open-source and because a mesh converter from the Salome mesh format to the Nemoh mesh format was available. Nemoh is then used for the calculation of the hydrodynamic coefficients which are based on linear potential flow theory. This theory considers small motions of the device compared to its characteristic dimension and to have negligible viscous forces compared to inertia forces. Small amplitude wave theory is used where the wave amplitudes are small in comparison with the wavelength.

The Bernoulli equation for unsteady potential flow is:

$$
\frac{\partial \phi}{\partial t}+\frac{1}{2}(\nabla \phi)^{2}+\frac{p}{\rho}+g z=0
$$


where linear theory neglects the quadratic term of this equation. The fluid potential is defined as follows:

$$
\vec{V}=\nabla \phi
$$

Where $\vec{V}$ is the flow velocity.

The Boundary Element Method (BEM) is then applied using Green's function to solve the radiation and diffraction problem. Irrotationality, incompressibility of the fluid and boundary conditions on body, bottom and free surface are considered in the solution.

The hydrodynamic coefficients found from Nemoh are transferred to WEC-Sim for the dynamic system simulation. This runs within MATLAB and a time domain solution is obtained.

The equation of motion for each body is solved based on Cummins' equation [28]:

$$
\left(m+A_{\infty}\right) \ddot{X}=-\int_{0}^{t} K(t-\tau) \dot{X}(\tau) d \tau+F_{\text {ext }}+F_{v i s}+F_{\text {res }}+F_{P T O}+F_{m o}
$$

where $m$ is the mass matrix, $A_{\infty}$ is the added mass matrix, $X$ is the displacement and rotational vector of the body, $K$ is the matrix of impulse response function, $F_{\text {ext }}, F_{v i s}, F_{r e s}, F_{\text {РTO }}$ and $F_{m o}$ are the vector of wave-excitation force, quadratic viscous drag force, net buoyancy restoring force, PTO force and the mooring force.

The power produced comes from a post-processing of simulation data. For each PTO line the power has been calculated as following:

$$
P=c_{P T O} \cdot v^{2}
$$

where $c_{\text {Рто }}$ is the PTO damping and $v$ is the PTO line speed. The total power is obtained as the sum of the PTO lines power (4 for each float).

The multi-float model which was tested in the tank in July 2017 was chosen for the comparison with the numerical model. The test used different regular waves equivalent to a full scale of $4 \mathrm{~m}$ wave height and a wave period between 7.5 and $10.5 \mathrm{~s}$ as described previously in Table 1 . This paper reports results for a regular wave of $4 \mathrm{~m}$ of wave height and $7.5 \mathrm{~s}$ wave period. A carefully selected analysis window equivalent to 100 seconds at full scale was used for each load bank setting. When the start-up is ignored, half of this duration (50s) is shown in the results to more clearly see the differences between the models in the graphs. For a better comparison with tank testing results, tank wave elevation has been simulated directly in WEC-Sim thanks to an existing simulation wave class option, "userDefined waves". A time difference due to the relative location of the wave probe and the device position has been observed and accounted for in the analysis. 
The inertia properties of the floats and of the reactor were calculated based on their simplified geometry (A hollow cylinder and 2 hemispheres for the float and a cuboid for the reactor). In this calculation the wall thickness of the float was adjusted so it had the same mass as the full scale model. The reactor has been considered to be a solid shape and its inertia properties were similar to the ones found by comparison to the 3D model properties in Autodesk Inventor of the CAD model of the test device (Relative error of inertia moments less than $5 \%$ ).

The height of the reactor was obtained from its simplified volume (Cuboid shape) equal to the real reactor physical volume characterized by the frame, ballast tanks and the PTO system. The float spacing has been set up to 2.25 times the diameter in the numerical simulation giving a relative error of less than $4 \%$ compared to the tank measured float spacing between the floats. Finally, the float depth has been set to an average of the experimental values of each float (Relative error less than $3 \%)$.

The mesh of the geometry was built in Salome-Meca [27] using triangle panels. A mesh independence study ensured that the hydrodynamic results were not dependent on the mesh resolution. In particular, 3 types of mesh have been considered: a coarse (172 panels for the float and 826 for the reactor), a moderate (1672 panels for the float and 1932 for the reactor) and a fine mesh (2916 panels for the float and 2830 for the reactor). Additionally, the fine mesh results were compared with output from the open-source OpenWarp [29]. This software improves Nemoh capability, includes parallel computing, and irregular frequency removal, and a fix of the switch between finite/infinite water depth. Nemoh switches between finite and infinite depth when the product between the wavenumber $(\mathrm{k})$ and the water depth $(\mathrm{d})$ is around 20 and this happens generally for the upper range of frequencies considered when intermediate depth is simulated.

It was found that the fine mesh with an increased number of panels was required to solve a problem in the results related to an overestimate of the roll and yaw motion in the time domain simulation. In particular, roll and yaw excitation coefficients of the floats (See Figure 6) are expected to be negligible due to the symmetry of the case. If this is not the case, some large motion in these degrees of freedom could happen which is increased by an amplification of the radiation coefficients in these modes. An example of radiation damping, added mass and excitation coefficients for the surge and heave motion relative to the float 1 and to the reactor are shown in Figure 6. A good mesh independence can be observed from the graphs where the 3 different mesh size give similar result. Moreover, reactor heave radiation damping and especially the added mass related to the heave motion of the reactor show the problem of Nemoh related to thin elements (See Figure 6d-6h). The behaviour of this coefficient is irregular for some frequencies and it is for 
now a limitation of Nemoh. Figure $6 \mathrm{~h}$ shows there is a reduction of the heave added mass of the reactor for frequencies above $1.6 \mathrm{rad} / \mathrm{s}$ for Nemoh but not for OpenWARP. This is because OpenWARP addresses the problem of the switching between intermediate and deep water. Small differences can be observed between Nemoh and OpenWARP in the calculation of the radiation impulse response function used in the time domain simulation. However, the verification of the effects of this difference is left as future work.

Finally, the fine mesh has been applied to the WEC-Sim simulations because a better accuracy of addressed using OpenWARP.

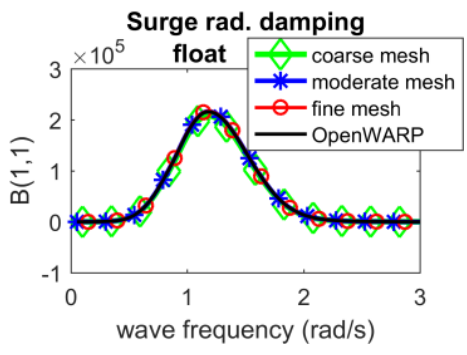

(a)

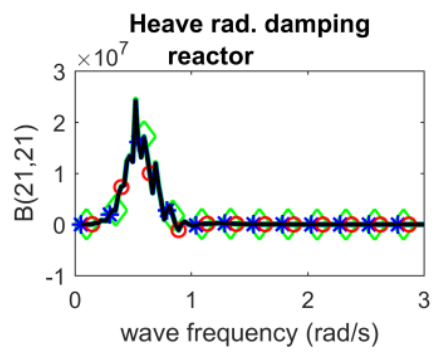

(d)

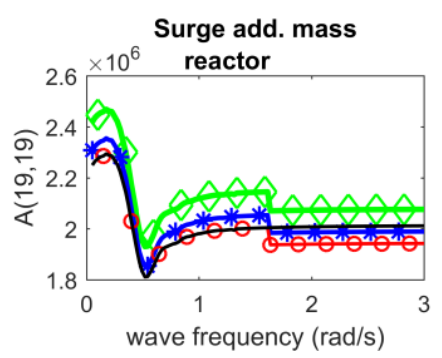

$(g)$

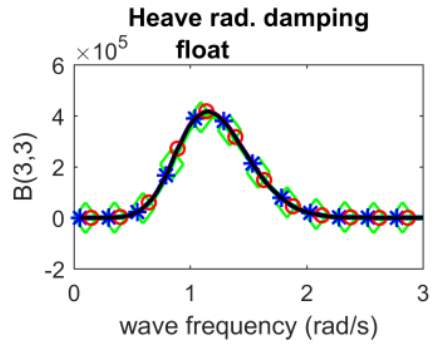

(b)

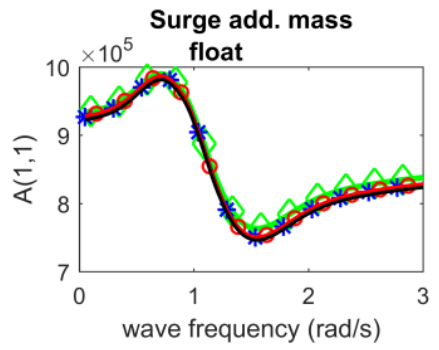

(e)

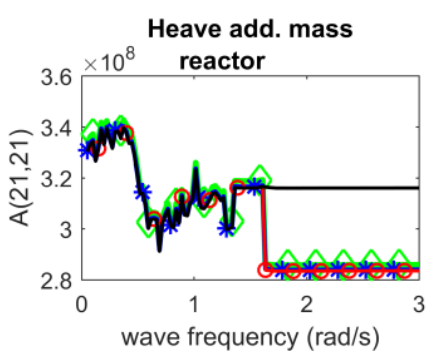

(h)

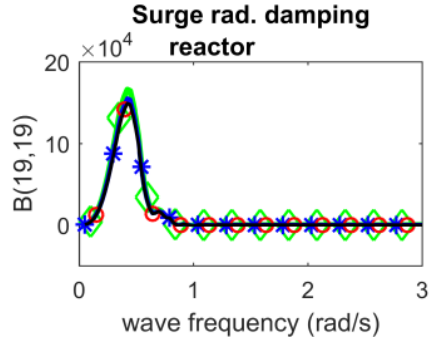

(c)

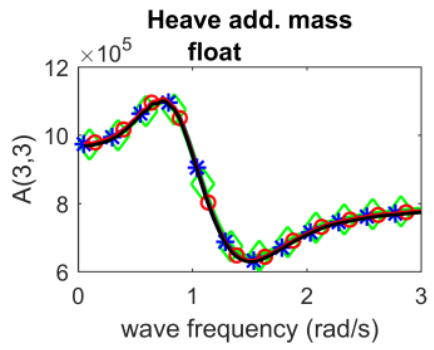

$(f)$

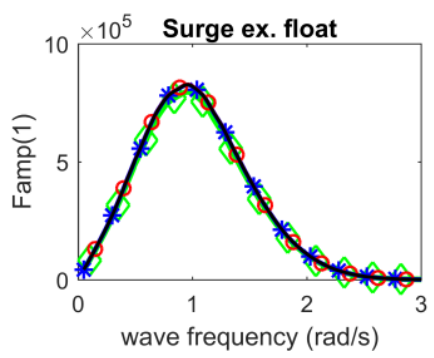

(i) 


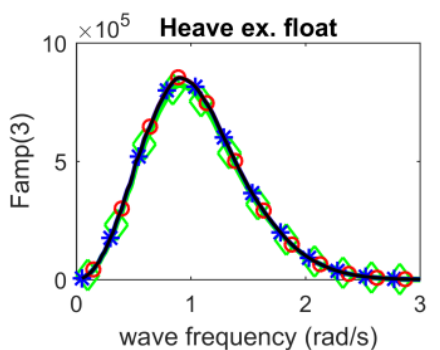

(j)

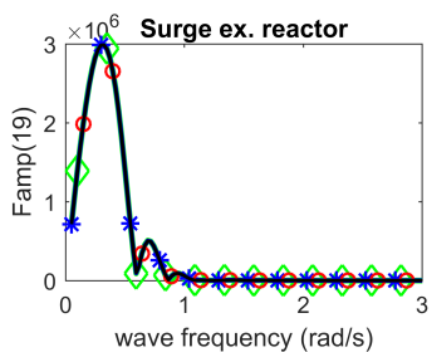

(m)

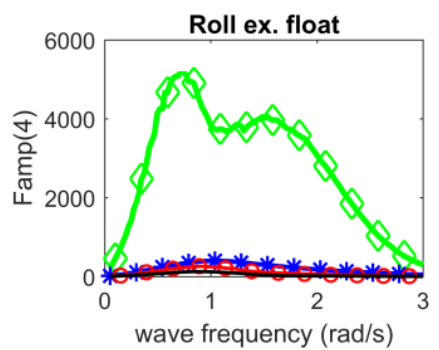

(k)

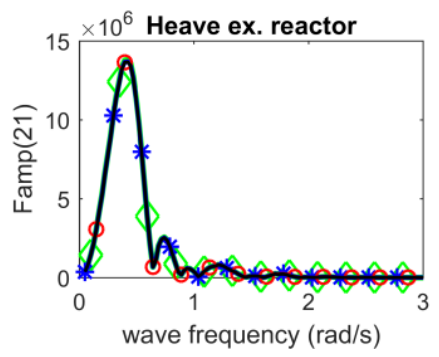

(n)

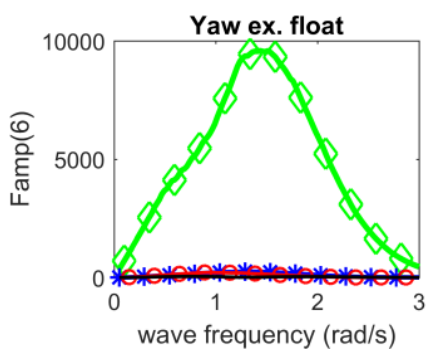

(l)

Figure 6: Surge and heave radiation damping coefficients of floatl for surge and heave motion of the float1 $(a, b)$, surge and heave radiation damping coefficients of reactor for surge and heave motion of the reactor $(c, d)$, surge and heave added mass coefficients of floatl for surge and heave motion of the floatl (e,f), surge and heave added mass coefficients of reactor for surge and heave motion of the reactor $(g, h)$, surge, heave, roll and yaw excitation coefficients of floatl ( $i, j, k, l)$, surge and heave excitation coefficients of reactor $(m, n)$. These coefficients refer to the full scale. (Single column image)

The PTO system was simplified to a linear spring and damper with a constant stiffness and damping, while the mooring was simplified to a constant stiffness spring. This is not entirely accurate because the strain-load relationship for the elastic materials used for the spring in the tank is not linear and therefore in future work a polynomial stiffness-load relationship should be used. In this work, the stiffness is related to the gradient of the strain-load relationship and it can be expressed as:

$$
k=\frac{d(\text { Load })}{d(\epsilon \cdot S F L)}
$$

where $\epsilon$ is the strain and $S F L$ is the Spring Free Length.

The static line tension of the central spring in the tank model was approximately $77 \mathrm{~kg}$ while it was approximately $3 \mathrm{~kg}$ for the corner spring (See Figure 7). The stiffness values for the numerical model were obtained as an average of the values between 1-5 kg for the corner spring and 50-100 $\mathrm{kg}$ for the central spring. 


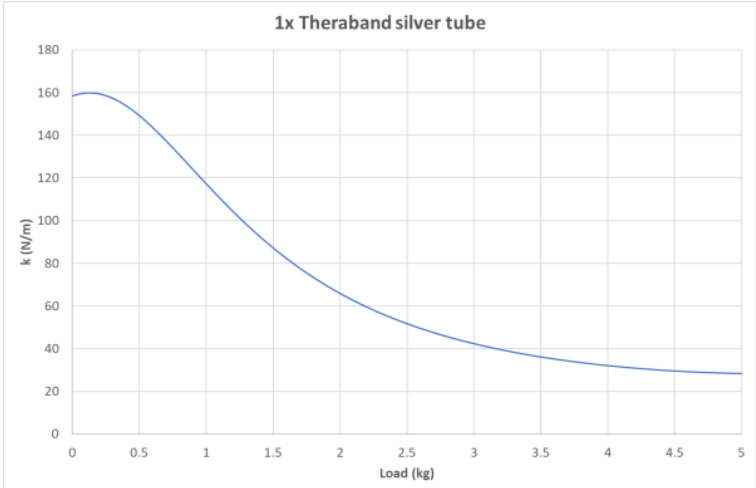

(a)

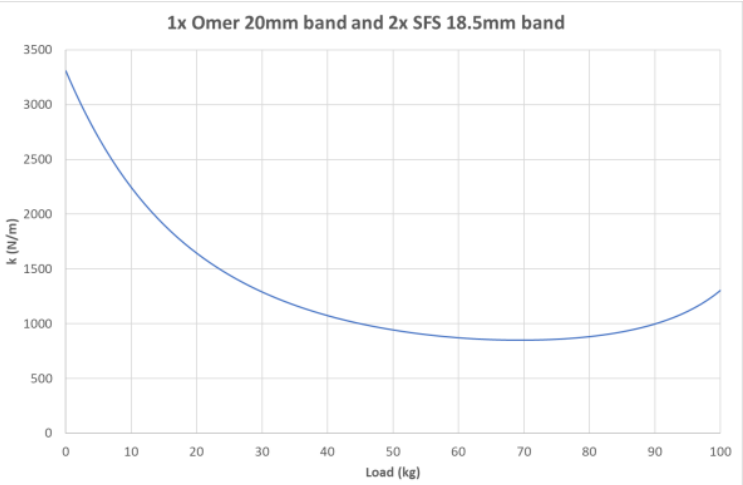

(b)

Figure 7: Stiffness as a function of the load of the 1x Theraband silver Tube used for the corner PTO lines (a) and of the 1x Omer $20 \mathrm{~mm}$ band and $2 x$ SFS $18.5 \mathrm{~mm}$ band used for the central line (b) at a tank scale. (Single column image) The relationship between the PTO line speed and the driving torque is linear, as observed in Figure 5, and can therefore be used to estimate a constant value for the damping as given by:

$$
c_{\text {PTO }}=\frac{T_{P T O}}{v_{P T O} \cdot \frac{D_{P T O}}{2}}
$$
where linear damping is СРTO, torque is T is D speed relationship. 


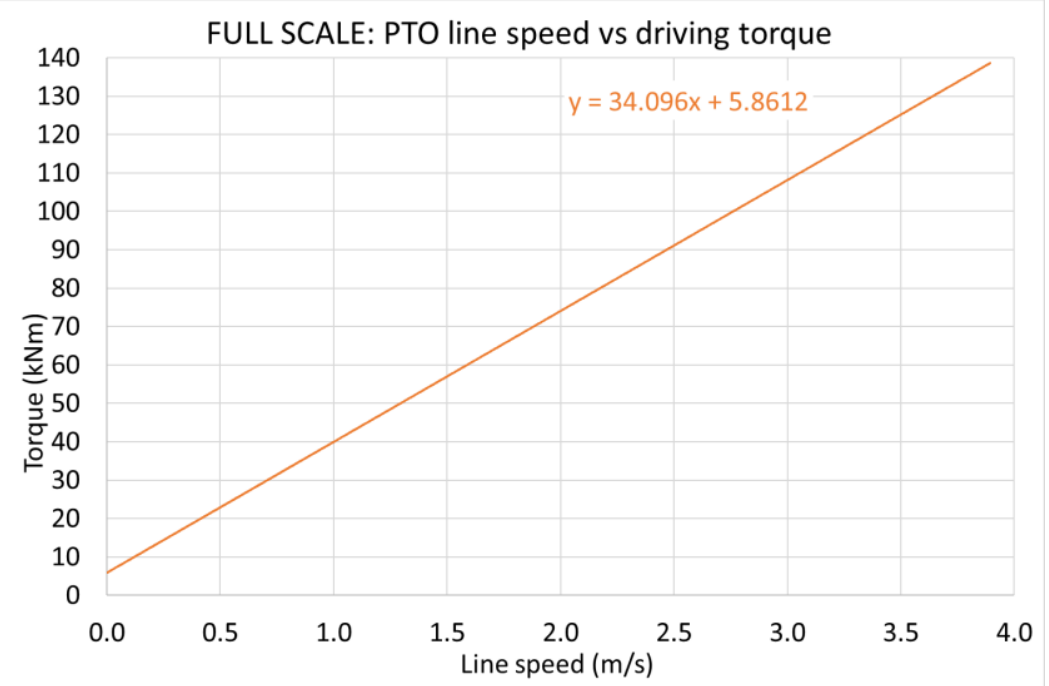

Figure 8: The full scale PTO line speed / driving torque linear relationship (Data scaled from a rig test of the 1:25 tank scale motor and load bank system). (Single column image)

There is an initial torque necessary to apply to the PTO to overcome friction before it starts moving (Constant term of the linear equation shown in Figure 5 and Figure 8). For this regular wave case the presumption is that it does not have a significant influence on the dynamic system because the floats are constantly moving but it could have some effects for an irregular wave case.

The mooring was a taut mooring. A Liros Magic Speed $5 \mathrm{~mm}$ line in polyester was used with a working stretch less than $8 \%$ defined as the elongation of a rope at $30 \%$ of its breaking load. The designed breaking load was $6800 \mathrm{~N}$. The load-strain diagram of the mooring line provided by Liros [30] was used to find an approximation of the mooring stiffness to be used in the numerical model. The load-strain relationship of the mooring line is almost linear and so the approximation with a constant stiffness value is quite good (See Figure 9). However, there could be different factors influencing this relation such as effects of the mean load, load range and cyclic period [31]. Moreover, the initial mooring line length was not the same for each corner of the reactor and this has introduced some non-linearity in the reactor motion. In the numerical set-up these different initial lengths have given a different spring value for each mooring line. 


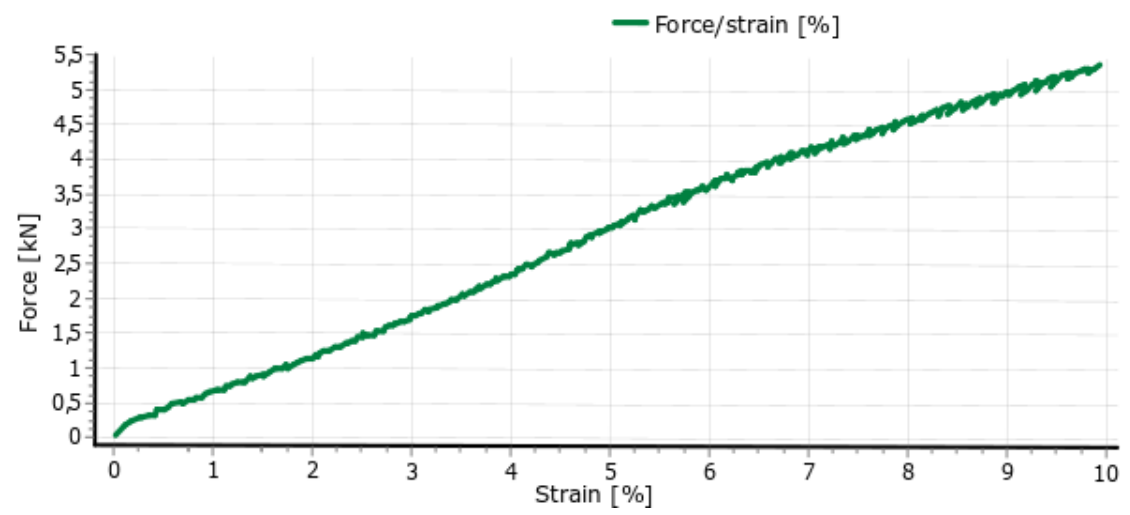

Figure 9: The strain-load relation of the Liros Magic Speed $5 \mathrm{~mm}$ mooring lines used in the tank testing [30].

The main factor that was difficult to define in the numerical model was the drag force on each float. A first estimation of the drag coefficient of 1.5 was used in the simulation based on previous research by Marine Power Systems Ltd [32]. This has been selected through a comparison of drag coefficients from spheres and cylinders found in the literature for example in [33]. After that, a process for tuning the estimate of the drag coefficient for each float was undertaken based on the comparison with the motion results of the tank testing. A drag coefficient has only been applied to the floats and not for the reactor because it is expected that drag force has a more significant importance relative to the inertia force when the characteristic dimension is less than $1 / 5$ th of the shortest wavelength [34] and the size of the reactor is significantly bigger than the float. Drag coefficient depends mainly on the geometry, Keulegan-Carpenter number, Reynolds number and surface roughness [33]. However due to lack of data relative to the shape of the float, an accurate result cannot be obtained from the literature.

The relation between drag coefficient and drag force used in the model is the following:

$$
\vec{D}=\frac{1}{2} C_{d} \rho A \vec{v}|\vec{v}|
$$

Where $A$ is the characteristic area of the body, $v$ is the body velocity, $C_{d}$ is the drag coefficient, $D$ is the drag force and $\rho$ is the density.

The drag coefficients for the floats of the single wave comparison described in the results section are shown in Table 2. The hydrodynamic heave drag coefficient was modelled as the default value (1.5) because heave float motion was also found to be related to the mechanical friction of the central float tether pulley system. In-fact, another experiment with a spring directly connected vertically to the float improved the matching of the heave motion with the numerical model. The majority of the load between the float and the reactor was concentrated in the central PTO line (around $87 \%$ ), therefore, it is assumed that most of the mechanical friction was also concentrated 

there. Measurement of the torque and of the line speed on the PTO spindle has been used to calculate the mechanical power produced and is influenced by mechanical losses such as bearing friction, bending work of the PTO lines and hysteresis losses (See Figure 10). This is very complex to understand fully and further investigation should be undertaken.

\begin{tabular}{|l|l|l|}
\hline & $\begin{array}{l}\text { Surge } \\
\text { hydrodynamic } \\
\text { drag coeff, Cd }\end{array}$ & $\begin{array}{l}\text { Heave } \\
\text { hydrodynamic } \\
\text { drag coeff, Cd }\end{array}$ \\
\hline Float1 & 2.5 & 1.5 \\
\hline Float2 & 2 & 1.5 \\
\hline Float3 & 1.3 & 1.5 \\
\hline
\end{tabular}

Table 2: The hydrodynamic drag coefficient used in the single wave comparison. These refer to the full scale

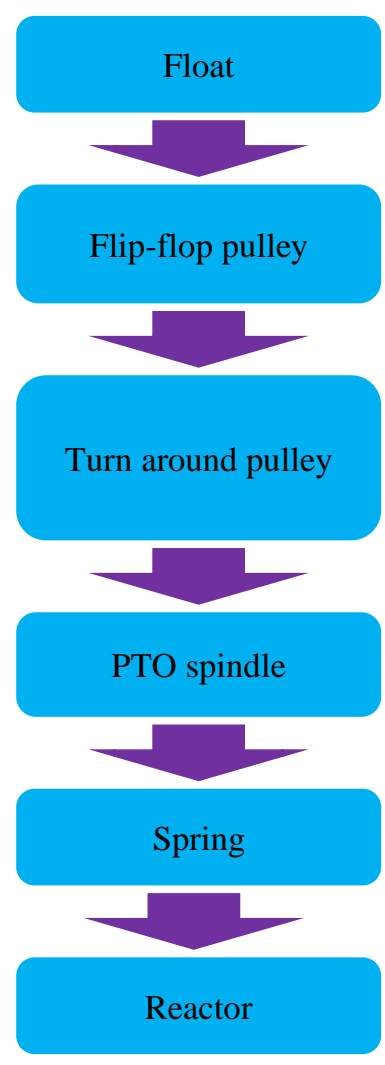

Bending work, roller bearing friction 
The mechanical friction of the central float tether pulley system was considered to match better the heave motion of the floats and modelled as a damping force. This damping force has been setup dependent on the float tether velocity and modelled as follows:

$$
F_{\text {damp }}=c \cdot v
$$

A damping coefficient of $1000 \mathrm{kNs} / \mathrm{m}$ has been used in the full scale numerical model for the detailed single wave comparison. The surge motion was not influenced significantly by the mechanical friction. In fact, the tuned hydrodynamic drag coefficients have sensible values compared to values that can be found in literature [33]. An interesting observation is that the tuned drag coefficient is different for each float. This is determined by the interference effects created by the hydrodynamic interactions between the floats. This phenomena is described in [33].

\section{Results and discussion}

\subsection{A detailed single wave case comparison}

This section describes the results from both the numerical and experimental tests relative to the regular wave of $4 \mathrm{~m}$ wave height and 7.5 wave period in full scale measurement. The tank testing data are compared with three different versions of the numerical model: a model that includes both hydrodynamic drag and mechanical friction, a model that takes into account only hydrodynamic drag and a model without drag. Results are described using the same simulation time period for the tank and numerical models. Hydrodynamic drag is tuned to match the surge motion amplitude between the numerical model and the tank (Relative difference less than 10\%). Mechanical friction is also tuned (Relative difference less than 20\%) but the accuracy is decreased because the same friction damping values are used for all the floats.

The parameters chosen for the numerical-physical comparison are the motion of the floats and reactor, forces and the power produced. Figure 11 shows the comparison of the reactor and floats motion and Response Amplitude Operator (RAO) in the main degrees of freedom. Main motions are the surge, heave and pitch motion due to the symmetry of the device relative to the verticallongitudinal plane of the wave direction. However small motions in sway, roll and yaw are expected in the tank due to setup uncertainties and in the numerical model due to numerical errors. Numerical errors are expected to decrease with an increase of the number of panels of the mesh. The results show the motions based on their average position without accounting for any offset values. Consistency between initial and final values has been checked for any error measurements. Overall there is a good comparison for the main degrees of freedom (Surge, Heave and Pitch) especially for the model including drag and mechanical friction. Amplitudes are reduced in surge 
and heave due to the drag effect. Drag in the pitch mode has not been accounted for in this comparison because it has a less important influence than surge and heave (See Table 3) but could be considered in further research. Floats orbit mainly in the surge-heave plane and become elliptical along the surge mode because the heave mode is reduced by mechanical friction (See Figure 11). A good matching of the phases for the main degrees of motion is obtained in this case considering that the same tank wave elevation and simulation time has been used. The RAO of the floats shows a very similar response in the frequency domain between the tank and the numerical model accounting for both drag and mechanical friction with a peak corresponding to the frequency of the regular wave simulated. The RAO of the reactor shows more differences between the tank and the numerical models mainly because of the more complex non-linear motion. The tank reactor response is characterized by various resonance frequencies that could be explained by the out of phase responses of the three floats, mooring settings and by tank wall reflection effects. The small motions of the reactor are more difficult to match correctly but it should be noted that these are negligible compared to float motion.

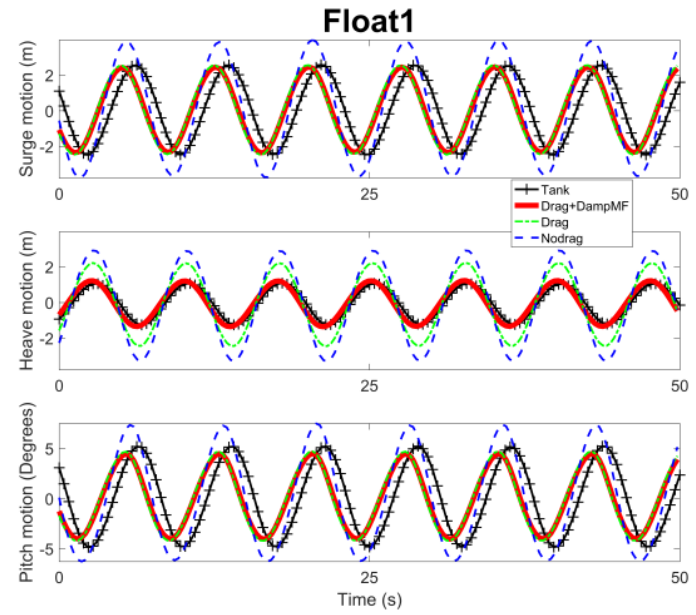

(a)
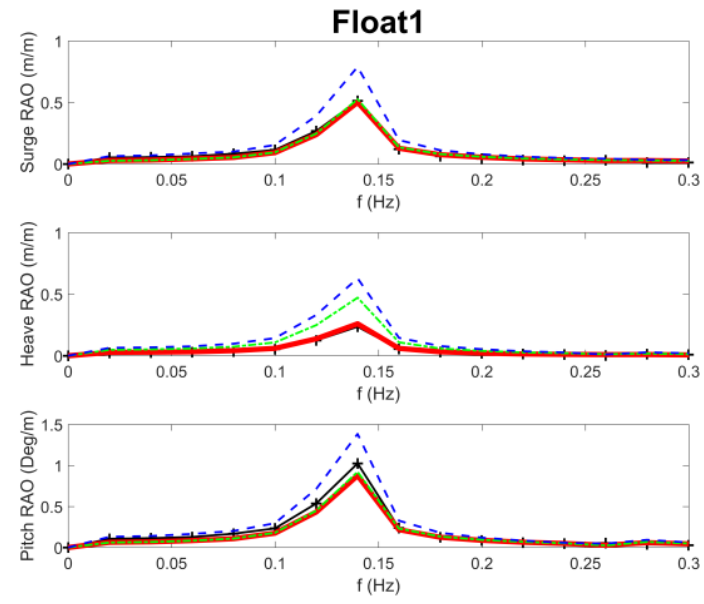

(b) 

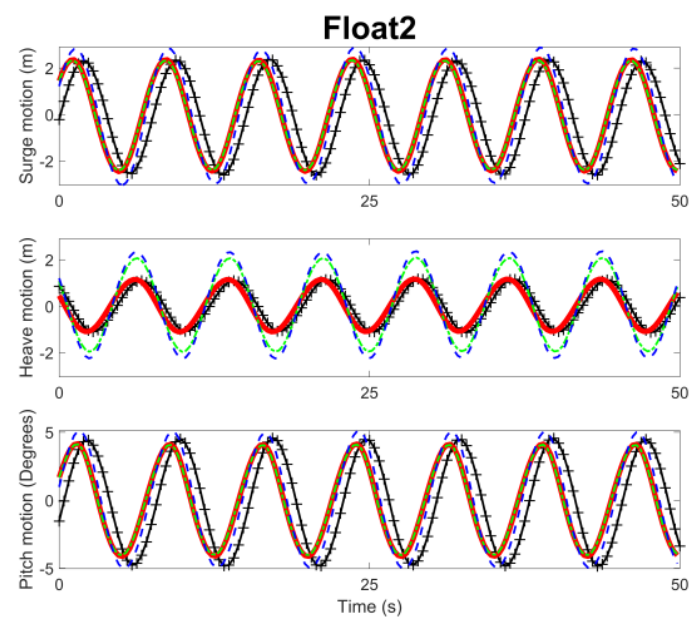

(c)
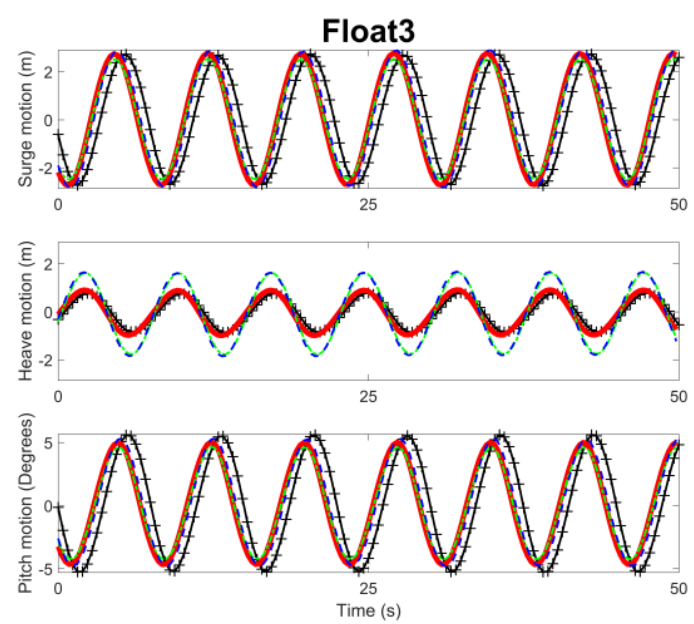

(e)
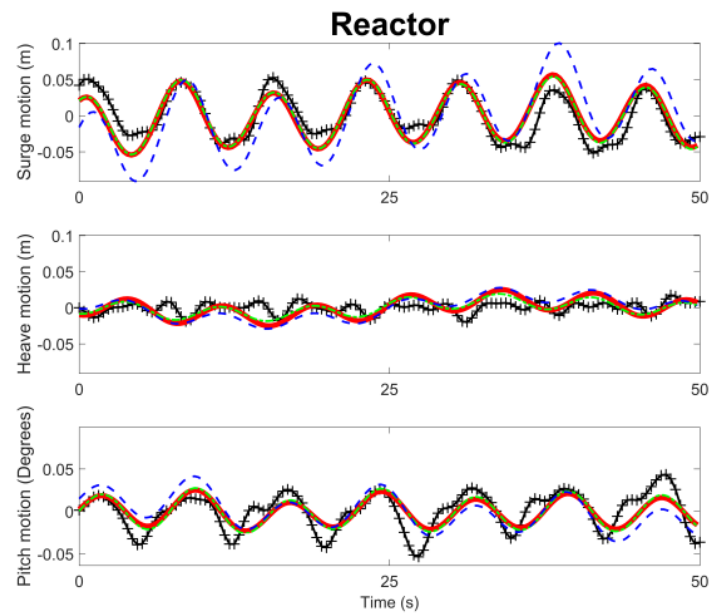

(g)
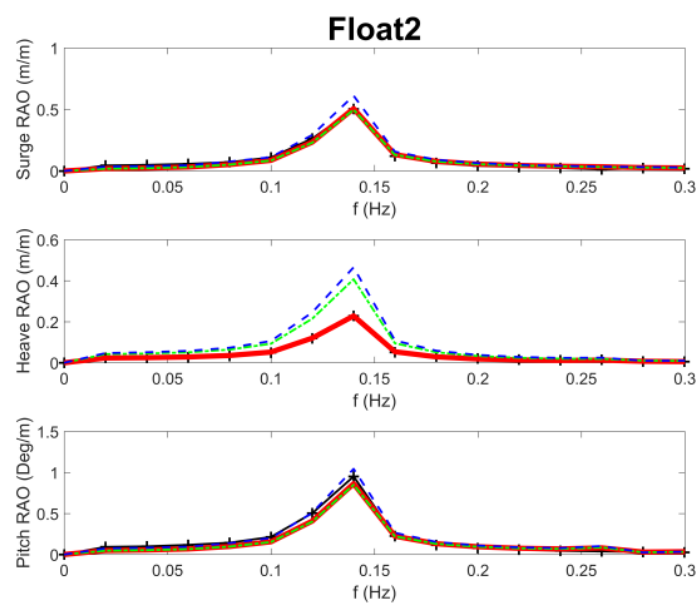

(d)
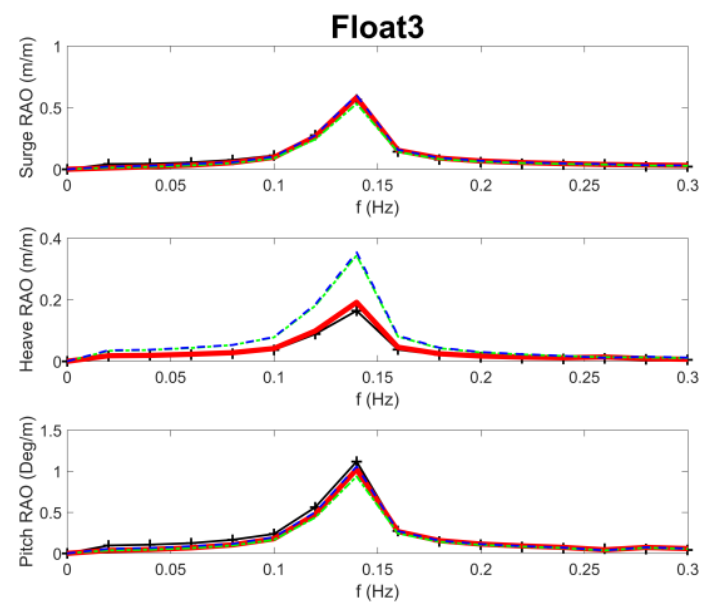

(f)
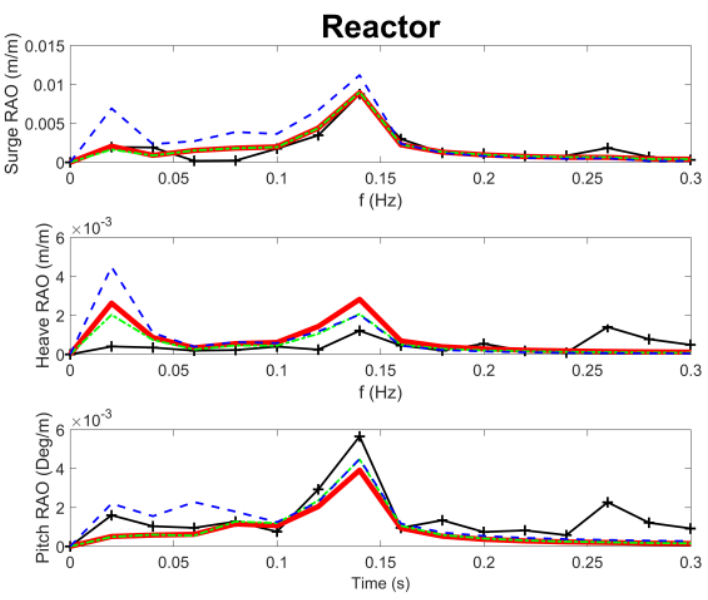

(h) 
Figure 11: Float1 motion and RAO (a-b), float2 motion and RAO (c-d), float3 motion and RAO $(e-f)$ and reactor motion and $R A O(g-h)$ at full scale of the 3 numerical models: drag + mechanical friction, drag, no-drag model and the tank testing. (Single column image)

Table 3 shows the relative error and the cross-correlation coefficients of the body motion amplitude in the different model predictions. Relative error has been obtained as following:

$$
R E(\%)=\frac{M_{T}-M_{m}}{M_{T}} \cdot 100
$$

Where $R E$ is the relative error, $M_{T}$ is the tank motion amplitude and $M_{m}$ is the numerical model motion amplitude.

The double amplitude has been used for the calculation of the relative error and obtained as a wave period average of the difference between the maximum and minimum excursions for a simulation time of fifteen times the wave period. Heave amplitude of the floats is not estimated well for models not including mechanical friction, while good agreement is found for the surge amplitude predicted by models accounting for hydrodynamic drag. Finally pitch motion is predicted with a good accuracy by all the numerical models for float 2 and float 3 but not for float 1 . However, the introduction of surge and heave drag provides a better match to this degree of freedom. Reactor tank amplitudes are more difficult to estimate correctly due to the small values. In a first approximation relative error based on the average double amplitude has been determined.

The cross-correlation coefficients are generally very high for the floats motion demonstrating a good similarity between the numerical models and the tank testing. However the coefficients relative to the reactor motion show instead lower values, especially for the heave motion.

Table 4 shows the Root Mean Square Deviation (RMSD) of the floats and of the reactor motion for the numerical models and the tank. The largest values of these are obtained for the model that doesn't account for drag as expected while generally the model that accounts for both drag and mechanical friction shows the most similar RMSD to the tank results.

\begin{tabular}{|l|l|l|l|l|}
\hline $\begin{array}{l}\text { Relative error/cross- } \\
\text { correlation }\end{array}$ & & Surge & Heave & Pitch \\
\hline \multirow{4}{*}{ Float1 } & Drag+DampMF & $4.893 / 0.982$ & $-11.635 / 0.994$ & $15.573 / 0.984$ \\
\cline { 2 - 5 } & Drag & $0.584 / 0.979$ & $-102.21 / 0.996$ & $11.485 / 0.982$ \\
\cline { 2 - 5 } & No Drag & $-51.08 / 0.989$ & $-168.672 / 0.998$ & $-35.198 / 0.99$ \\
\hline \multirow{4}{*}{ Float2 } & Drag+DampMF & $2.797 / 0.981$ & $-0.726 / 0.992$ & $11.677 / 0.983$ \\
\cline { 2 - 5 } & Drag & $4.531 / 0.98$ & $-79.359 / 0.995$ & $13.141 / 0.982$ \\
\cline { 2 - 5 } & No Drag & $-18.446 / 0.987$ & $-104.428 / 0.994$ & $-7.628 / 0.988$ \\
\hline \multirow{2}{*}{ Float3 } & Drag+DampMF & $-0.78 / 0.98$ & $-15.756 / 0.994$ & $10.905 / 0.981$ \\
\cline { 2 - 4 } & Drag & $7.901 / 0.981$ & $-107.902 / 0.996$ & $18.352 / 0.983$ \\
\hline
\end{tabular}




\begin{tabular}{|l|l|l|l|l|}
\hline \multirow{3}{*}{ Reactor } & No Drag & $-4.253 / 0.986$ & $-113.594 / 0.995$ & $7.271 / 0.987$ \\
\cline { 2 - 5 } & Drag+DampMF & $-4.779 / 0.858$ & $-4.632 / 0.442$ & $39.921 / 0.81$ \\
\cline { 2 - 5 } & Drag & $-5.345 / 0.87$ & $22.897 / 0.434$ & $31.771 / 0.823$ \\
\cline { 2 - 4 } & No Drag & $-33.844 / 0.686$ & $22.65 / 0.365$ & $29.503 / 0.598$ \\
\hline
\end{tabular}

Table 3: Relative error (\%) on the double amplitude of motion of the floats and the reactor and the cross-correlation coefficients between the numerical models and the tank at a full scale.

\begin{tabular}{|l|l|l|l|l|}
\hline $\begin{array}{l}\text { Root mean square } \\
\text { error }\end{array}$ & & Surge & Heave & Pitch \\
\hline Float1 & Drag+DampMF & 1.697 & 0.895 & 2.983 \\
\cline { 2 - 5 } & Drag & 1.776 & 1.624 & 3.131 \\
\cline { 2 - 5 } & No Drag & 2.686 & 2.166 & 4.749 \\
\cline { 2 - 5 } & Tank & 1.764 & 0.812 & 3.526 \\
\hline \multirow{5}{*}{ Float2 } & Drag+DampMF & 1.708 & 0.786 & 2.919 \\
\cline { 2 - 5 } & Drag & 1.677 & 1.402 & 2.873 \\
\cline { 2 - 5 } & No Drag & 2.072 & 1.602 & 3.549 \\
\cline { 2 - 5 } & Tank & 1.73 & 0.783 & 3.271 \\
\hline \multirow{5}{*}{ Float3 } & Drag+DampMF & 1.957 & 0.657 & 3.446 \\
\cline { 2 - 5 } & Drag & 1.789 & 1.183 & 3.156 \\
\cline { 2 - 5 } & No Drag & 2.024 & 1.218 & 3.578 \\
\cline { 2 - 5 } & Tank & 1.924 & 0.568 & 3.815 \\
\hline & Drag+DampMF & 0.032 & 0.012 & 0.014 \\
\cline { 2 - 5 } & Drag & 0.032 & 0.009 & 0.016 \\
\cline { 2 - 4 } & No Drag & 0.046 & 0.015 & 0.019 \\
\cline { 2 - 4 } & Tank & 0.031 & 0.008 & 0.022 \\
\hline
\end{tabular}

Table 4: The root mean square deviation of the floats and the reactor motion for the numerical models and the tank at a full scale.

To show data obtained from the numerical models that is representative of the whole system, Figure 12 shows the main forces of float 1 and the mooring forces. Most of the forces have a regular response; the mooring forces are more irregular due to the different spring values set-up in each corner cable. The excitation force as expected is not dependent on the model because it depends only on the wave and hydrodynamic coefficients. The forces due to the added mass and radiation damping are instead also dependent on the response of the system (acceleration and velocity of the body respectively) and so their values change with the model used. In particular, the most significant values are obtained for the surge and heave mode. PTO forces and drag forces of float 1 show a clear dependence on the drag coefficient. PTO forces are reduced by an increase of the drag coefficient. Drag forces are larger in surge than in heave because velocities reach higher values in this degree mode as shown also from the main motion in surge in Figure 11. A reduced heave drag force is obtained for the model accounting for drag and mechanical friction than the 
model accounting only for drag because of the mechanical friction that decreases the heave motion $444 \quad$ and velocities.
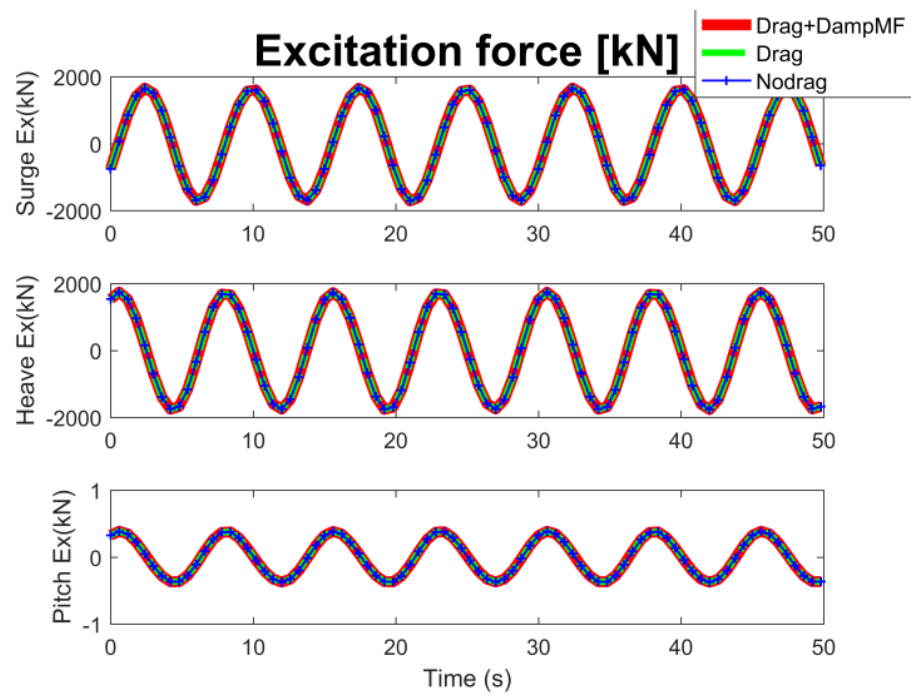

(a)
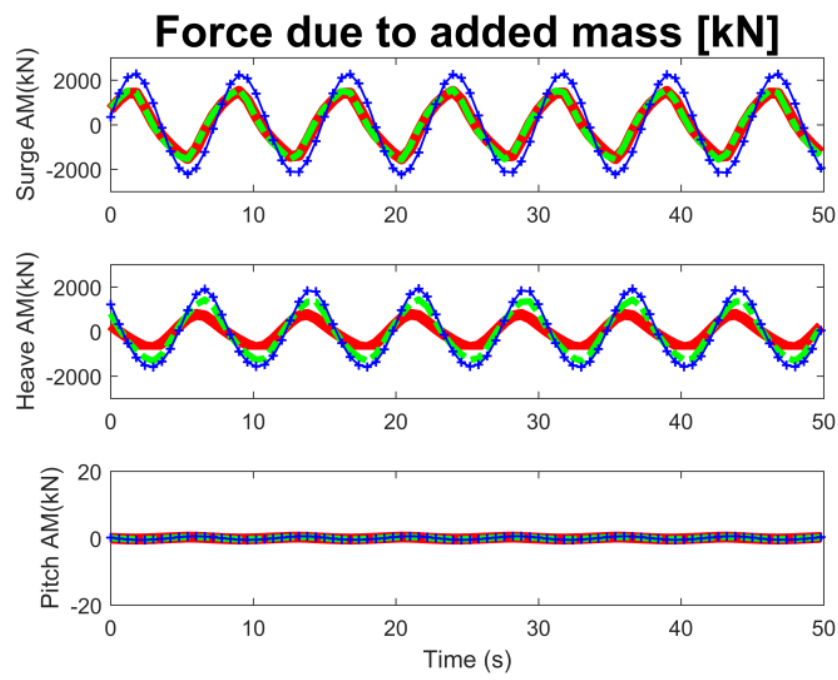

(b) 

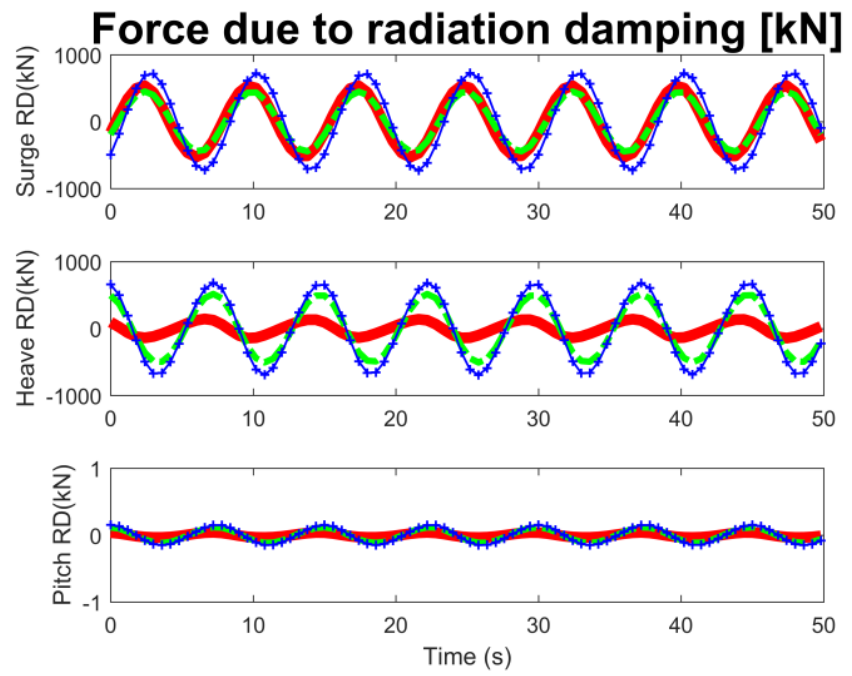

(c)
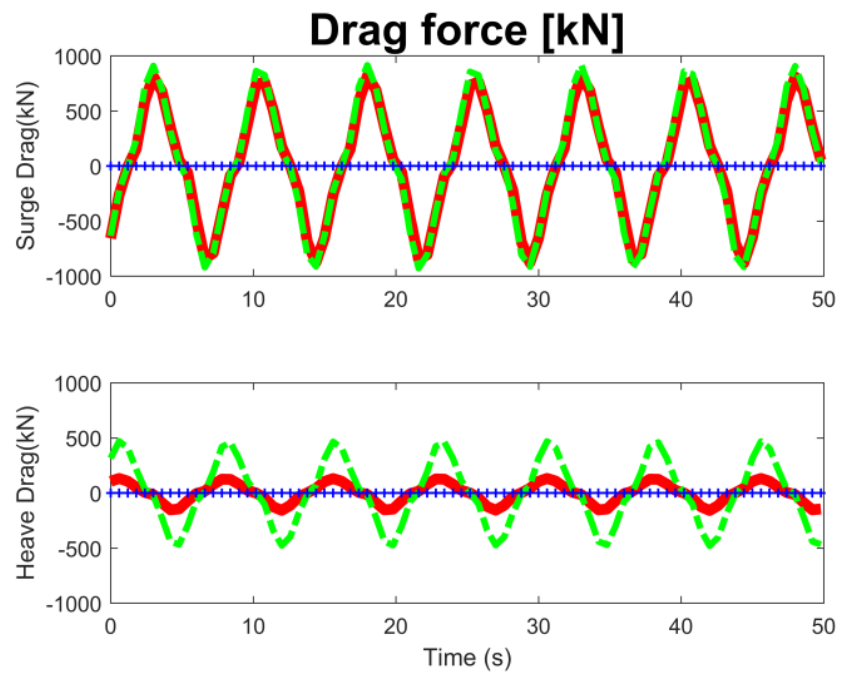

(d)
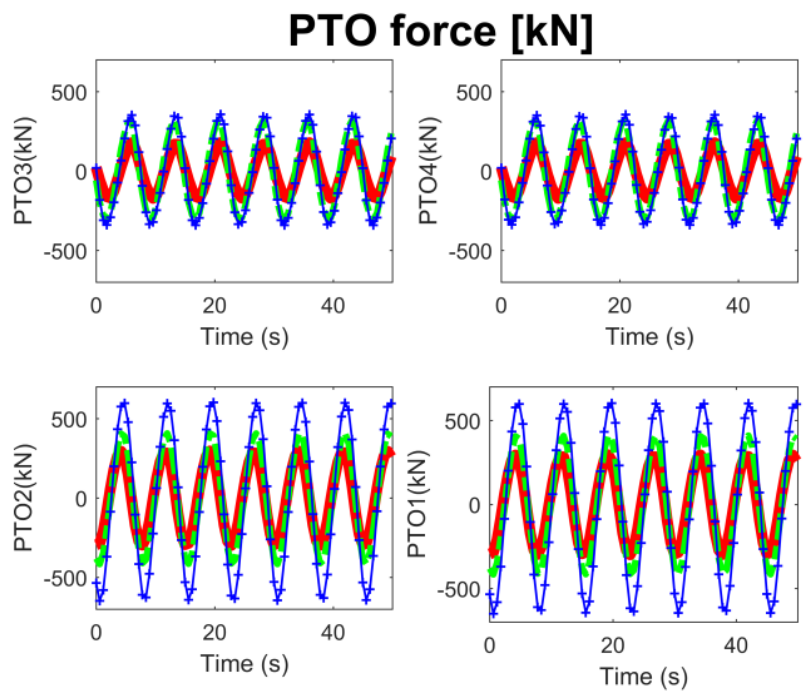

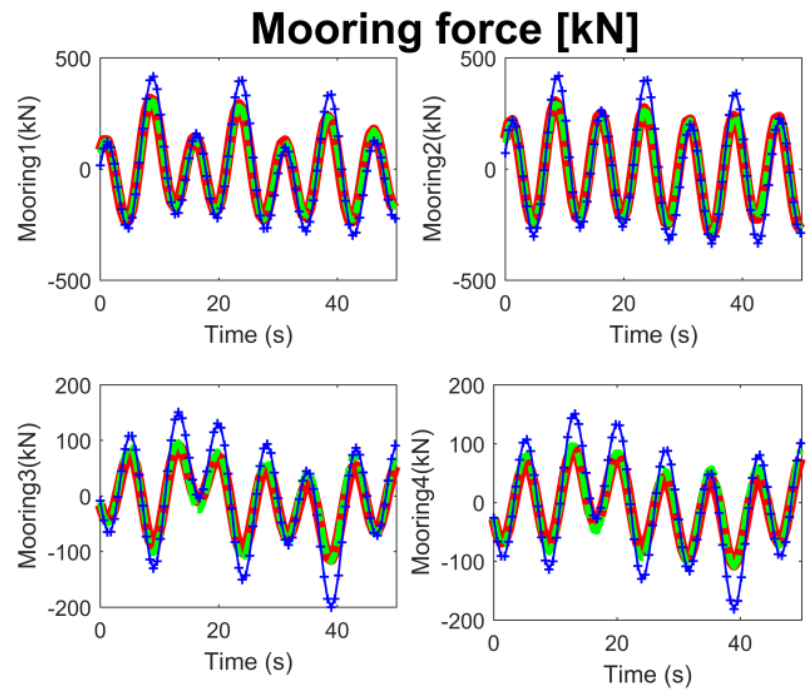

Figure 12: Forces acting on the WEC at a full scale: the excitation force (a), the force due to the added mass (b), the force due to the radiation damping $(c)$, the drag force $(d)$, the PTO forces $(e)$ and the mooring forces for each corner mooring cable (f). 3 numerical models are compared: the drag + mechanical friction, the drag and the no-drag model. The hydrodynamic and PTO forces are referred to floatl. (Single column image)

The PTO torque is shown in Figure 13. There is a good comparison for the torque of PTO3-4 while there is an overestimation for PTO1-2. This behaviour is related with the PTO lines velocities because the damping coefficient is a constant of the numerical model. So, the peaks of the PTO velocities for PTO1-2 are smaller for the tank testing. However, there is the same behaviour of 467 larger PTO line velocities of PTO3-4 than PTO1-2. In particular, mechanical friction plays an important role for the determination of the tank torque. 

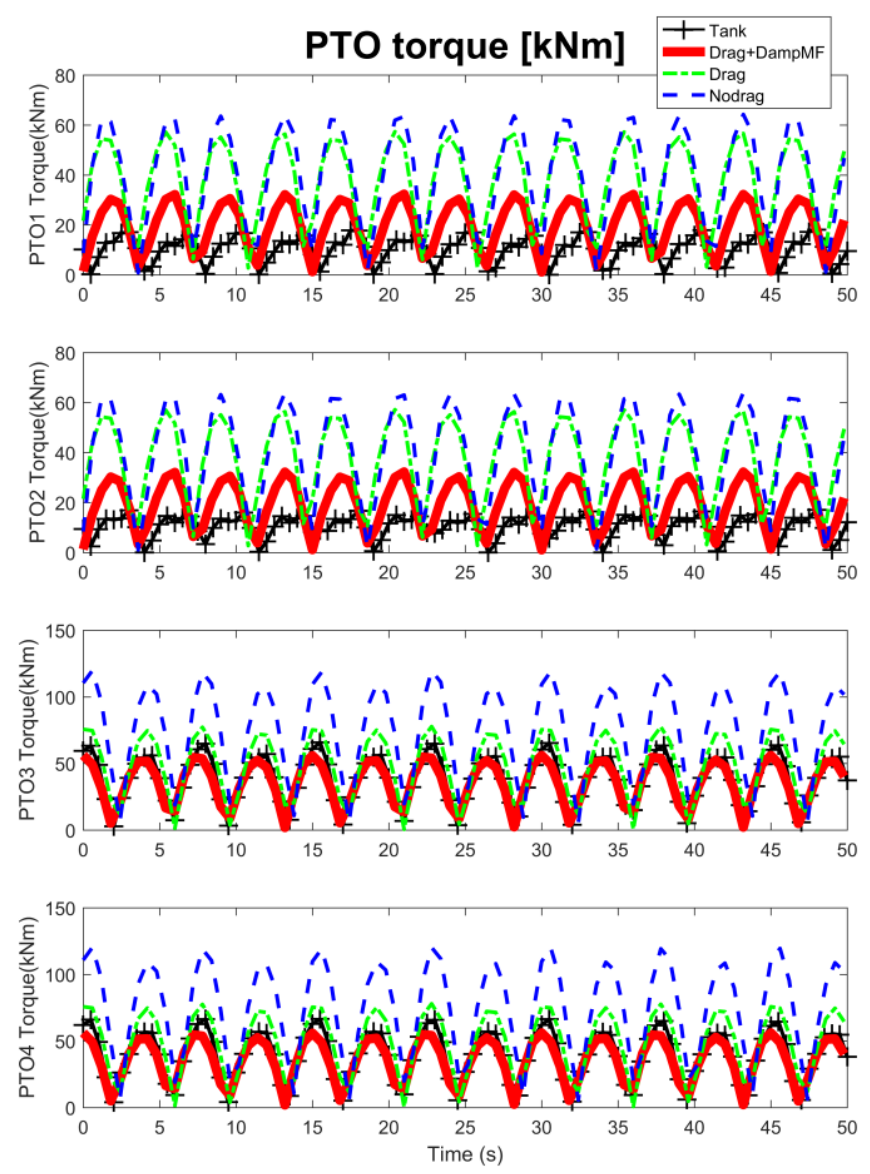

469

Figure 13: PTO Torque of float1 for each PTO line at a full scale. (Single column image)

Finally, the mechanical power has been compared for the same time period as the motion comparison (See Figure 14). The mechanical power from the tank testing results has been obtained as following:

$$
P_{\text {tank }}=\frac{T_{P T O}}{\frac{D_{P T O}}{2}} \cdot v_{P T O}
$$

As expected, the numerical model without accounting for drag and mechanical friction in the heave motion overestimates the mean total power by more than $150 \%$ compared to the tank testing. There is a good agreement between the tank test result and the model accounting for drag and mechanical friction. In particular, the relative difference on the mean total power for this model is less than $1 \%$. There is also a good matching in the phase of the power for all models, but the amplitude is highly influenced by the drag and mechanical friction. Finally, the normalized power produced by the models is reported in Table 5. 


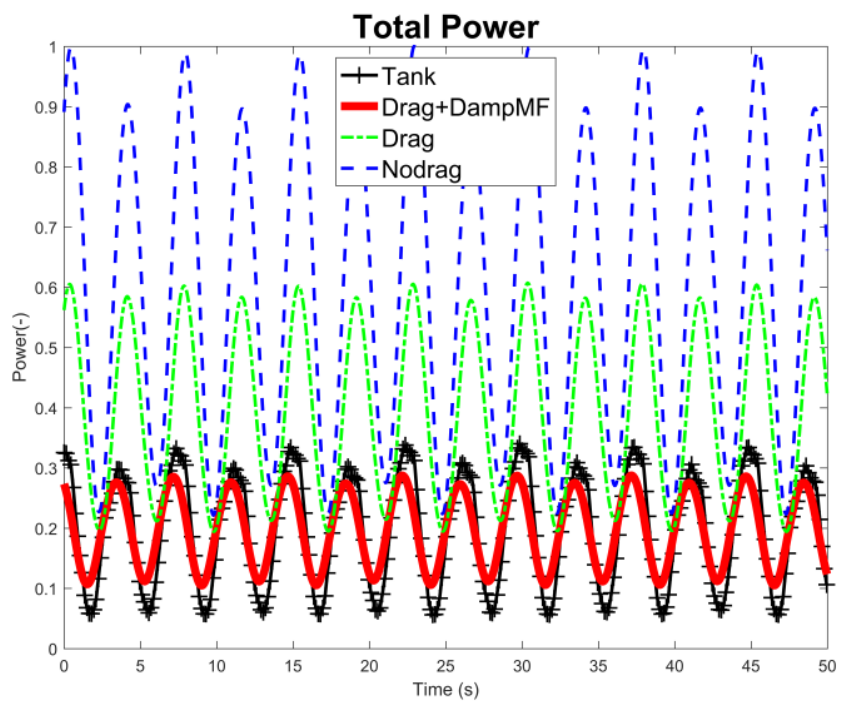

Figure 14: Total normalized power at a full scale of the tank testing and the 3 numerical models: the drag + mechanical friction, the drag and the no-drag model. (Single column image)

\begin{tabular}{|c|c|c|c|}
\hline & & $\begin{array}{l}\text { Amplitude } \\
(-)\end{array}$ & $\begin{array}{l}\text { Mean } \\
(-)\end{array}$ \\
\hline \multirow[t]{4}{*}{ Float1 } & Drag+DampMF & 0.10 & 0.12 \\
\hline & Drag & 0.27 & 0.27 \\
\hline & No Drag & 0.61 & 0.52 \\
\hline & Tank & 0.19 & 0.12 \\
\hline \multirow[t]{4}{*}{ Float2 } & Drag+DampMF & 0.09 & 0.10 \\
\hline & Drag & 0.21 & 0.21 \\
\hline & No Drag & 0.34 & 0.29 \\
\hline & Tank & 0.14 & 0.11 \\
\hline \multirow[t]{4}{*}{ Float3 } & Drag+DampMF & 0.11 & 0.11 \\
\hline & Drag & 0.16 & 0.17 \\
\hline & No Drag & 0.23 & 0.20 \\
\hline & Tank & 0.14 & 0.10 \\
\hline \multirow{4}{*}{$\begin{array}{l}\text { Total } \\
\text { Power }\end{array}$} & Drag+DampMF & 0.24 & 0.33 \\
\hline & Drag & 0.56 & 0.66 \\
\hline & No Drag & 1.00 & 1.00 \\
\hline & Tank & 0.38 & 0.33 \\
\hline
\end{tabular}


Table 5: The normalized power double amplitudes and normalized mean values of the power produced in the tank and in the numerical models at a full scale.

\subsection{Regular wave cases}

Different regular waves have been tested and compared with the numerical model. Two main numerical models have been tested for the comparison with the tank testing results: a tuned drag model and a default one. The tuned drag model considers a tuned surge drag coefficient for each float, a default heave drag coefficient of 1.5 and a tuned damping coefficient to represent the mechanical friction on the central PTO line. Tuned surge drag coefficient are obtained after a process to match similar surge motion amplitude results between the numerical and the tank model (Relative difference in surge less than $10 \%$ and less than $30 \%$ in heave). Heave motion is tuned through a central PTO line damping coefficient but the accuracy is limited because the same value has been used for each float (See Figure 17). The default model considers a drag coefficient of 1.5 in surge and heave and a damping coefficient of $1000 \mathrm{kNs} / \mathrm{m}$. Preliminary drag coefficient values come from previous research [32]. The default damping coefficient has been set up equal to the first case considered in previous section.

The accuracy of the numerical model depends on the estimation of the tuned drag coefficient and so it is important to find any relation with simulation results or parameters. However, a large amount of experimental data is necessary to investigate the drag coefficient for each specific condition. More specifically the numerical model needs to be tested and validated for different PTO settings and irregular waves. A huge amount of work is necessary for this and here is shown only a comparison for regular waves with the same wave height $(4 \mathrm{~m})$ and different wave periods (From 7.5 to $10.5 \mathrm{~s}$ ).

A good relation between the tuned drag coefficients and the Keulegan Carpenter number (KC) has been found (See Figure 15). Keulegan-Carpenter number is calculated as following:

$$
K C=\frac{V \cdot T}{D}
$$

Where $\mathrm{V}$ is the amplitude of the body velocity, $T$ is the wave period and $D$ is the float diameter. There is an increase of the tuned drag coefficient for smaller $\mathrm{KC}$ values. This behavior can be found also in experimental results of Sarpkaya [35]. In this work the drag coefficients has been determined as a function of the $\mathrm{KC}$ number for cylinders that could be used in a first approximation for a comparison with the tuned drag coefficients of the floats.

Tuned drag coefficients for each float are not the same because of the interference effects explained by Sarpkaya [33]. However most of these are in a similar range between 0.5 and 1 . 
Figure 16 shows the tuned damping coefficients for the mechanical friction on the central PTO line. In particular, there is an increase with the wave period. This behavior is difficult to explain because the mechanical friction is very difficult to characterize correctly (See Figure 10). The determination of the mechanical friction has been investigated in [36]. In this work the friction damping was found out to be related by a linear function of the 2-norm of the buoy velocity. This further investigation of the mechanical friction applied to this case is left for further possible future work. Figure 17 shows the heave and surge amplitudes of the 3 floats and it shows that the heave values are significantly smaller than the surge amplitudes and reach very low values for higher wave periods. Surge amplitudes are instead increasing as a function of the wave period and reach a peak for a wave period between 9.5 and $10 \mathrm{~s}$. This different behavior is due to the mechanical friction of the PTO lines because hydrodynamic coefficients show instead a similar resonance frequency (See Figure 6). The default model shows an overestimation of the heave motion and an underestimation in surge. While the first behavior is related to an underestimation of mechanical friction forces, the second is due to the large default drag coefficient in surge used. Float1 has the largest surge amplitudes that are then reduced from float1 to float3.

Finally, the normalized power of each float and the total power is shown in Figure 18. The numerical models are underestimating the mean power with a relative error in average around $10 \%$ for each float and around $6 \%$ for the total average power. Relative error is calculated as following:

$$
R E(\%)=\frac{P_{T}-P_{m}}{P_{T}} \cdot 100
$$

Where $R E$ is the relative error, $P_{T}$ is the tank mean power and $P_{m}$ is the numerical model mean power.

Float1 is the float that produces more power as expected because it shows the largest amplitude motion compared to the other 2 floats. Peak of the mean power is obtained around 9.5s. Float 3 shows a more non-linear behaviour with a double peak around 9 and 10s, probably influenced by hydrodynamic interaction effects. 


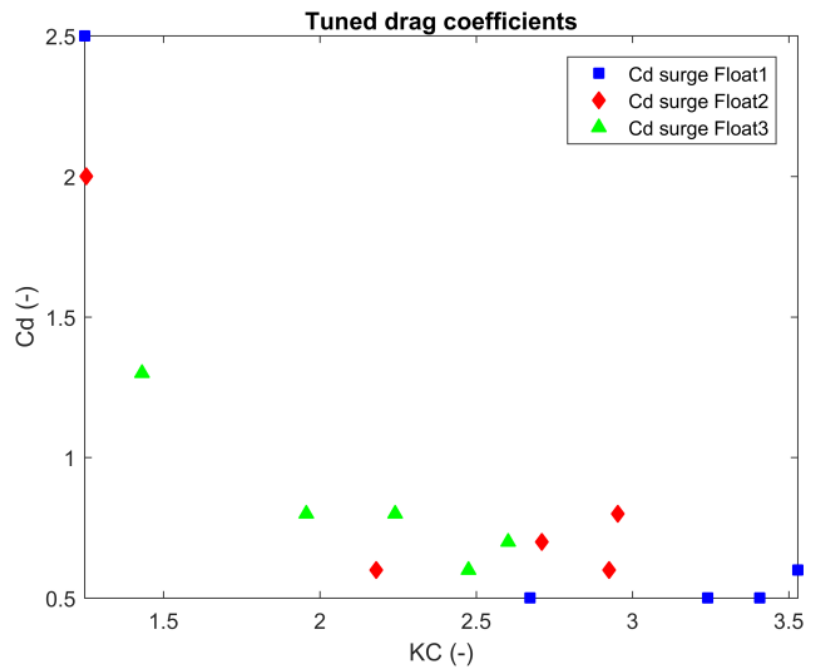

Figure 15: Tuned surge drag coefficients of the 3 floats as a function of the Keulegan-Carpenter number for 6 different regular waves at a full scale. (Single column image)

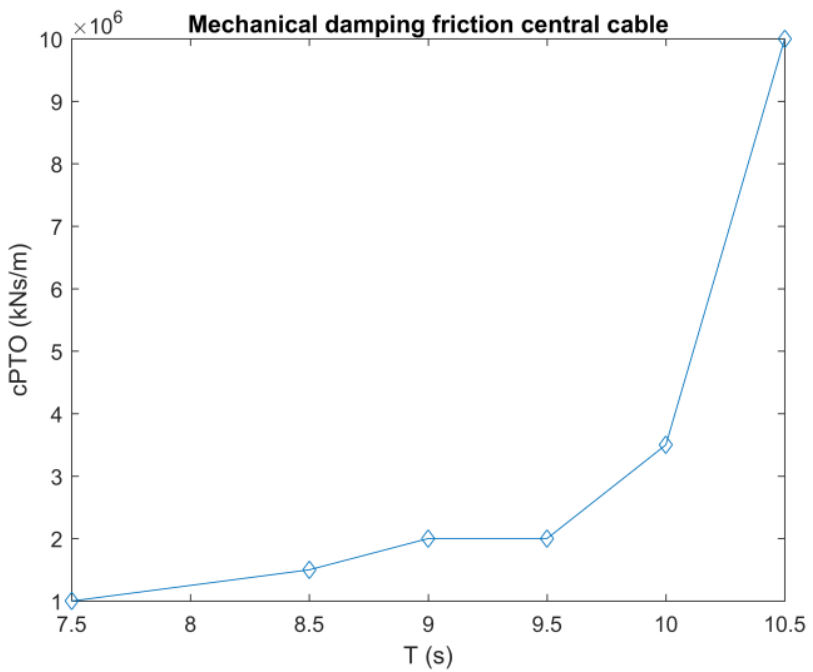




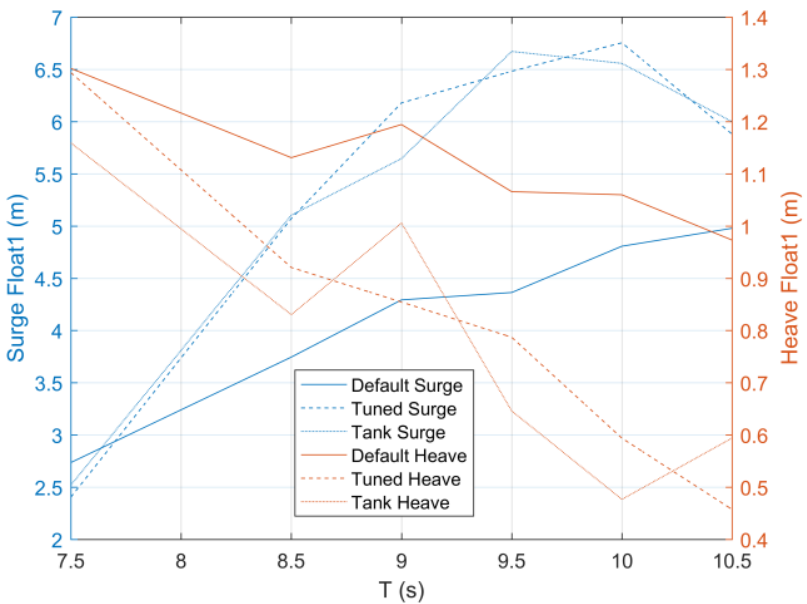

(a)
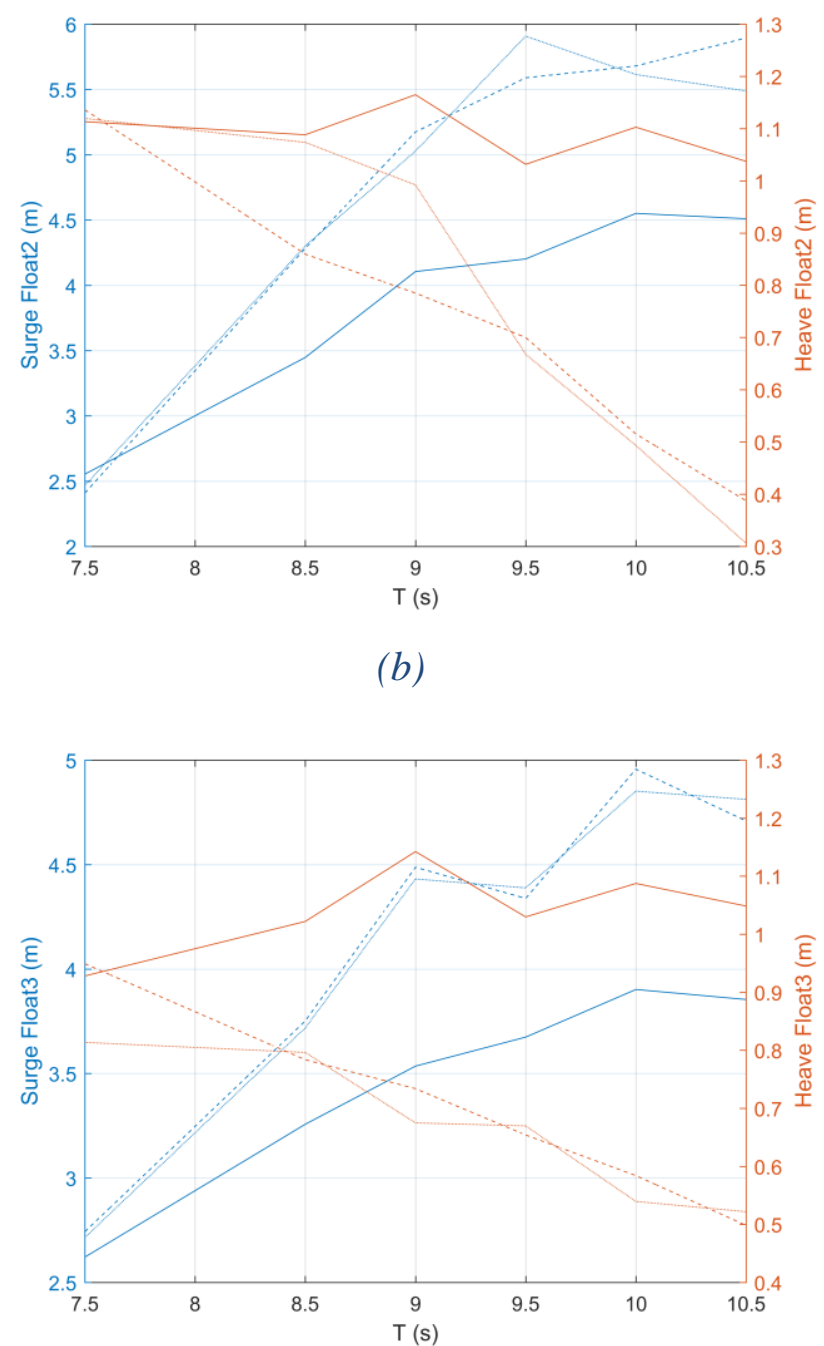

(c) numerical models and for the tank testing at a full scale. (Single column image) 

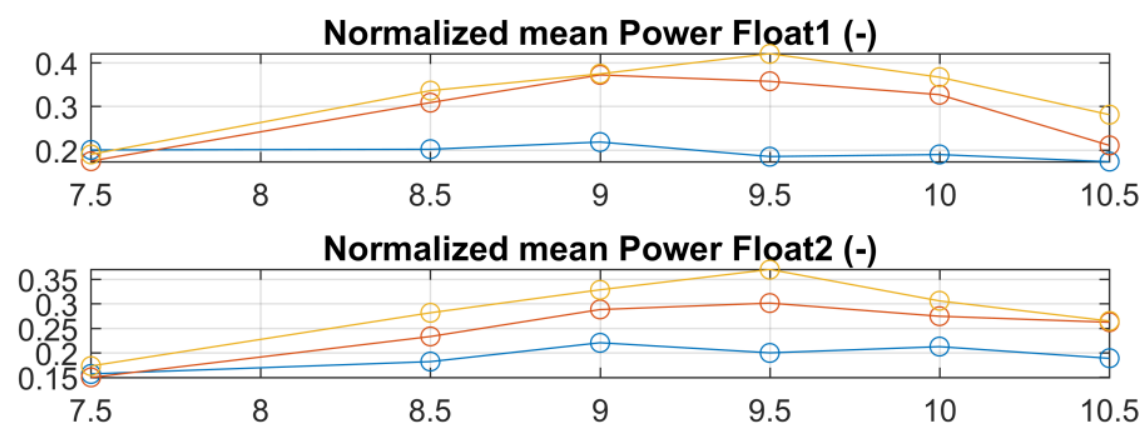

Normalized mean Power Float3 (-)

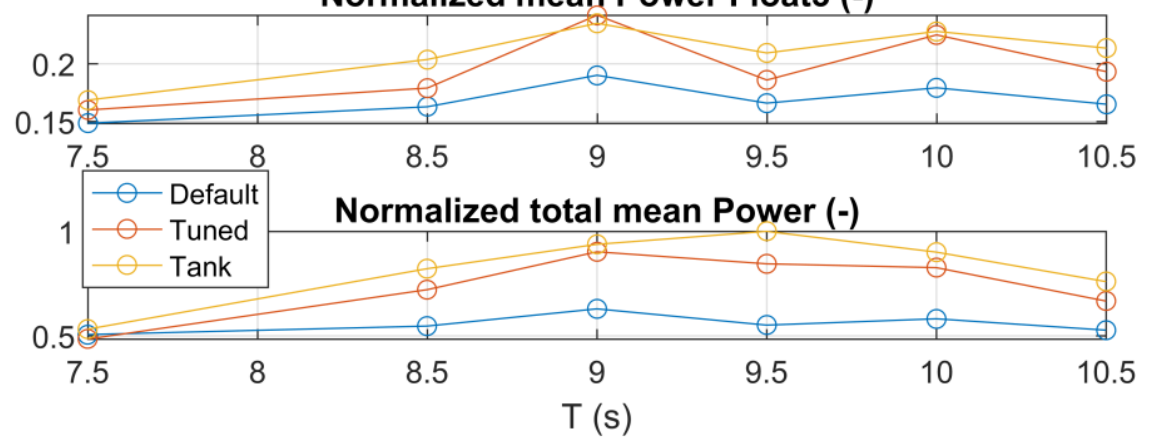

Figure 18: Normalized mean power of each float and of the total system for the default and tuned numerical models and for the tank testing at a full scale. (Single column image)

\section{Conclusions}

A comparison between the tank testing of a multi float $1 / 25^{\text {th }}$ scale model of the WaveSub and various numerical models has been made. It is demonstrated that a numerical model that accounts for both hydrodynamic drag and mechanical friction could estimate accurately the motion and the power produced from the tank testing. Numerical models that, instead, don't account for these 2 effects are overpredicting the power produced. A limitation of this approach is that a process of tuning of the drag coefficient is necessary to determine a realistic drag associated with the motion of the floats. However, these results are a first step towards a process of validation of the numerical model associated to the WaveSub device.

The benchmark has been analysed in full scale using a Froude scaling because the hydrodynamic software is more computationally stable at full scale. Hydrodynamic forces can be Froude scaled because viscosity is not accounted for in the computation. Then PTO forces and mooring forces have been linearized and so they can also be Froude scaled. The main purpose of this paper was not to obtain the most realistic full scale representation, but to compare the numerical model and the tank data. A more realistic representation of the full scale should take in account scaling effects for PTO, mooring and drag forces. 
Historically, the main assumption of the hydrodynamic computation has been to neglect viscous effects. However, a realistic hydrodynamic drag force has been introduced in the time-domain simulation to match better the experimental results. Different tuned drag coefficients have been identified especially for the surge motion of the float and this will require further investigation to understand the influence of the particular geometric configuration. It is clear that there is a trend relating to the $\mathrm{KC}$ number and this should be the starting point for further work. A further damping force has been added to account for the reduced heave motion of the floats probably due to mechanical friction in the pulleys. In particular, this friction was found to be mainly related to the pulley of the central cable where there was the majority of the load (90\%). Future investigation to reduce the mechanical friction is related to a reduction of the total load on the PTO lines and understanding the relation between load and the amount of power produced.

Finally, a good benchmarking has been achieved for the model accounting for both drag and mechanical friction. A comparison of results has been reported for the motion amplitudes and for the power produced by the device for a specific regular wave case. Then different regular waves have been tested and tuned for a specific drag coefficient and mechanical damping. Power in particular has been matched well with the damping and friction values chosen, reaching a relative mean total power difference around $10 \%$.

Further work will include an investigation of different PTO settings and irregular waves. Tank testing results from different load bank settings can be compared with the numerical model which corresponds to different PTO damping coefficient. Then irregular waves and multi-directional waves [37] can be also considered to represent a more realistic sea state and power capture. Relationship between Keulegan-Carpenter number and drag coefficient can be then verified for these new cases. Additionally, mechanical friction of the central float tether pulley assembly is still also a topic of further research.

\section{Acknowledgments}

Thanks to Sue Alstom of Swansea University for providing the rubber material stiffness datasets. Ian Masters acknowledges support from EPSRC through the United Kingdom Centre for Marine Energy Research (EP/P008682/1). This research is also supported by the Knowledge Economy Skills Scholarships (KESS 2). It is a pan-Wales higher level skills initiative led by Bangor University on behalf of the HE sector in Wales. It is part funded by the Welsh Government's European Social Fund (ESF) convergence programme for West Wales and the Valleys. Design, manufacture and testing of the 1/25th WaveSub model was part of 'The Multi Float WaveSub 
Wave Energy Convertor (WEC)' project, supported by Innovate UK under the Energy Catalyst Round 3 Early Stage competition.

\section{References}

[1] J. Cruz, Ocean wave energy: current status and future perspectives, Springer Science \& Business Media, 2007

[2] A. Falcão, Wave energy utilization: A review of the technologies, Renewable and Sustainable Energy Reviews, Volume 14, Issue 3, 2010

[3] Marine Power Systems Ltd, WaveSub. http://marinepowersystems.co.uk/ (accessed September 2018).

[4] R. Clare, D. V. Evans, T. L. Shaw, Harnessing sea wave energy by a submerged cylinder device, Proceedings of the Institution of Civil Engineers, 1982

[5] Plymouth Ocean Wave Basin. https://www.plymouth.ac.uk/research/institutes/marineinstitute/coast-laboratory (accessed September 2018)

[6] FaB Test. http://www.fabtest.com/ (accessed September 2018)

[7] A. Falcão, Modelling of wave energy conversion, Instituto Superior Técnico, Universidade Técnica de Lisboa, 2013.

[8] A. Babarit, G. Delhommeau (2015). Theoretical and numerical aspects of the open source bem solver nemoh. In 11th European Wave and Tidal Energy Conference (EWTEC2015).

[9] T. Parisella, Comparison of open-source code nemoh with wamit for cargo ship motions in shallow water, in Centre for Marine Science and Technology, Curtin University, 2016.

[10] M. Penalba, T. Kelly, and J. Ringwood. "Using NEMOH for modelling wave energy converters: a comparative study with WAMIT." Centre for Ocean Energy Research (COER), Maynooth University, Co. Kildare, Ireland (2017).

[11] C.-H. Lee, J. N. Newman, Wamit user manual, WAMIT, Inc, 2006.

[12] WEC-Sim code, https://wec-sim.github.io/WEC-Sim/ (accessed September 2018)

[13] K. Ruehl, C. Michelen, S. Kanner, M. Lawson, and Y. Yu, Preliminary Verification and Validation of WEC-Sim, an Open-Source Wave Energy Converter Design Tool, in Proceedings of the 33rd International Conference on Ocean, Offshore and Arctic Engineering, OMAE 2014, San Francisco, CA, 2014.

[14] A. Combourieu, M. Lawson, A. Babarit, K. Ruehl, A. Roy, R. Costello, P. L. Weywada, and H. Bailey, WEC3: Wave Energy Converters modeling Code Comparison project, in Proceedings of the 11th European Wave and Tidal Conference, EWTEC 2015, Nantes, France, 2015. 
[15] F. Wendt et al., International Energy Agency Ocean Energy Systems Task 10 Wave Energy Converter Modeling Verification and Validation, in Proceedings of the 12th European Wave and Tidal Conference, EWTEC 2017, Cork, Ireland, 2017.

[16] M. Lawson, B. Garzon, F. Wendt, Y. Yu, and C. Michelen, COER Hydrodynamics Modeling Competition: Modeling the Dynamic Response of a Floating Body Using the WEC-SIM and FAST Simulation Tools, in Proceedings of the 34th International Conference on Ocean, Offshore and Arctic Engineering, OMAE 2015, St. John's, Newfoundland, Canada, 2015.

[17] B. Bosma, K. Ruehl, A. Simmons, B. Gunawan, P. Lomonaco, and C. Kelley, WEC-Sim Phase 1 Validation Testing - Experimental Setup and Initial Results, in Proceedings of the 35th International Conference on Ocean, Offshore and Arctic Engineering, OMAE 2016, Busan, South Korea, 2016.

[18] K. Ruehl, C. Michelen, B. Bosma, and Y.-H. Yu, WEC-Sim Phase 1 Validation Testing Numerical Modeling of Experiments, in Proceedings of the 35th International Conference on Ocean, Offshore and Arctic Engineering, OMAE 2016, Busan, South Korea, 2016.

[19] C. Whitlam, The multi float wavesub wave energy convertor (WEC), in IUK Project 132392, 2017.

[20] J. Mankins. Technology readiness levels. White Paper, April 6 (1995).

[21] Qualysis. https://www.qualisys.com/ (accessed September 2018).

[22] EC 90 flat $\varnothing 90 \mathrm{~mm}$, brushless, 90 Watt, with Hall sensors. https://www.maxonmotor.com/medias/sys_master/root/8825435389982/17-EN-271.pdf (accessed June 2018).

[23] RM44 encoder-sensor base unit. Available at: https://www.rls.si/en/rm44-up-to-13-bitencoder-base-unit (accessed June 2018).

[24] Rheostats (Potentiometers) Wirewound. http://www.ohmite.com/cat/controls rheostats.pdf (accessed June 2018).

[25] Thera-Band Tubing 30m Silver (super Heavy). https://www.thera-bands.co.uk/thera-banddispenser-boxes/104-thera-band-tubing-30m-tan.html (accessed June 2018).

[26] E. Faraggiana, I. Masters, J. Chapman, Design of an optimization scheme for the WaveSub array. RENEW 2018 Conference Proceedings.

[27] Salome-Meca. https://www.code-aster.org/spip.php?article303 (accessed September 2018). [28] W. Cummins, The impulse response function and ship motions, DTIC Document, Tech. Rep., 1962.

[29] OpenWarp, http://nrel.github.io/OpenWARP/ (accessed October 2018). 
[30] Liros Magic Speed. https://www.liros.com/en/products/productfinder/details/detail/lirosmagic-speed.html (accessed June 2018).

[31] N. Casey, S. Banfield. Factors affecting the measurement of axial stiffness of polyester deepwater mooring rope under sinusoidal loading. InOffshore Technology Conference 2005 Jan 1. Offshore Technology Conference.

[32] Marine Power Systems Ltd, Research of drag coefficients for the float of the wavesub, Swansea, Tech. Rep.

[33] T. Sarpkaya, Wave forces on offshore structures. Cambridge university press, 2010.

[34] A. Ansys, Theory manual. release 15.0, 2013.

[35] T. Sarpkaya, In-line and transverse forces on smooth and rough cylinders in oscillatory flow at high Reynolds numbers, Monterey, California. Naval Postgraduate School, Tech. Rep., 1986.

[36] G. Bacelli, R. Coe, D. Patterson, D. Wilson, System Identification of a Heaving Point Absorber: Design of Experiment and Device Modeling, Energies, Multidisciplinary Digital Publishing Institute, 2017, 10, 472.

[37] E. Faraggiana, I. Masters, J. Chapman, G. Foster, G. Stockman, Multi-directional waves and time domain perturbed field visualization of theWaveSub device. EWTEC 2019 Conference Proceedings. 